\title{
əTransient Aggregation of Convection: Observed Behavior and Underlying Processes
}

\author{
Hirohiko Masunaga, ${ }^{\mathrm{a}}$ CHristopher E. Holloway, ${ }^{\mathrm{b}}$ Hironari KanAmori, ${ }^{\mathrm{a}}$ SANDrine Bony, \\ AND THORWALD H. M. STEIN ${ }^{\mathrm{b}}$

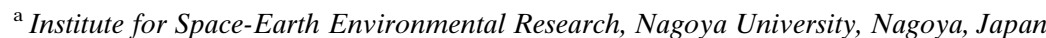 \\ ${ }^{\mathrm{b}}$ Department of Meteorology, University of Reading, Reading, United Kingdom \\ ${ }^{\mathrm{c}}$ LMD/IPSL, CNRS, Sorbonne Universities, University Pierre and Marie Curie, Paris, France
}

(Manuscript received 12 December 2019, in final form 30 September 2020)

\begin{abstract}
Convective self-aggregation is among the most striking features emerging from radiative-convective equilibrium simulations, but its relevance to convective disturbances observed in the real atmosphere remains under debate. This work seeks the observational signals of convective aggregation intrinsic to the life cycle of cloud clusters. To this end, composite time series of the Simple Convective Aggregation Index (SCAI), a metric of aggregation, and other variables from satellite measurements are constructed around the temporal maxima of precipitation. All the parameters analyzed are large-scale means over $10^{\circ} \times 10^{\circ}$ domains. The composite evolution for heavy precipitation regimes shows that cloud clusters are gathered into fewer members during a period of $\pm 12 \mathrm{~h}$ as precipitation picks up. The high-cloud cover per cluster expands as the number of clusters drops, suggesting a transient occurrence of convective aggregation. The sign of the transient aggregation is less evident or entirely absent in light precipitation regimes. An energy budget analysis is performed in search of the physical processes underlying the transient aggregation. The column moist static energy (MSE) accumulates before the precipitation peak and dissipates after, accounted for primarily by the horizontal MSE advection. The domainaveraged column radiative cooling is greater in a more aggregated composite than in a less aggregated one, although the role of radiative-convective feedback behind this remains unclear.
\end{abstract}

KEYWORDS: Tropics; Convection; Convective clouds; Satellite observations

\section{Introduction}

Convective self-aggregation is a form of spontaneous symmetry breaking that is known to occur under particular conditions in an idealized atmosphere under radiativeconvective equilibrium (RCE). Unlike traditional convective organization such as the formation of mesoscale convective systems (Houze 2004, and references therein), selfaggregation involves a whole set of thermodynamic processes involved in the expanding clear-sky environment as well as the areas of convection being increasingly localized over time. While pioneering work reporting such phenomena underscored the roles of moisture for the localization of convection (Held et al. 1993; Tompkins and Craig 1998; Tompkins 2001), Bretherton et al. (2005), who first used the term "convective self-aggregation" in the literature, analyzed their RCE simulations in light of the atmospheric energy budget and found radiative feedbacks to be particularly important in addition to the moisture feedback for convective self-aggregation. It was confirmed in subsequent studies that the radiative contrast across the clear and cloudy skies promotes self-aggregation through, for instance, a muted longwave cooling by high clouds (Stephens et al. 2008) and an enhanced lower-atmospheric cooling by low clouds in

\footnotetext{
D Denotes content that is immediately available upon publication as open access.
}

Corresponding author: Hirohiko Masunaga, masunaga@ nagoya-u.jp dry areas (Muller and Held 2012). Otherwise the physical processes crucial for convective self-aggregation are not fully understood. The occurrence or absence of selfaggregation can be sensitive to numerical model setups such as the domain size and grid resolution (Muller and Held 2012; Jeevanjee and Romps 2013). Wing and Emanuel (2014) found that self-aggregation does not occur over ocean surfaces colder than $300 \mathrm{~K}$, while signs of convective self-aggregation are evident for a broader range of SST in other studies (Coppin and Bony 2015; Holloway and Woolnough 2016; Wing and Cronin 2016) [a thorough review on the sensitivity to SST is provided by Wing (2019)]. Aspects of self-aggregation learned from idealized simulations are confirmed also in numerical runs with realistic configurations, with a potentially similar magnitude sensitivity to cloud radiative interactions when accounting for effects of boundary conditions on the limited-area realistic runs (Holloway 2017). Theoretical models have been developed to explain convective self-aggregation in terms of an instability intrinsic to moisture-convection interactions (Craig and Mack 2013) or inherent in the interplay of radiative cooling with tropospheric water vapor (Emanuel et al. 2014) and the production of available potential energy primarily in the boundary layer (Yang 2018). A more comprehensive review is found in Wing et al. (2017) and Wing (2019).

Signs of convective aggregation have been sought in observations to test its relevance to the real atmosphere [see review by Holloway et al. (2017)]. The atmosphere tends to be drier and less cloudy, and thus more efficient in longwave radiative cooling in a more aggregated state (Tobin et al. 2012, 2013), 
(a)

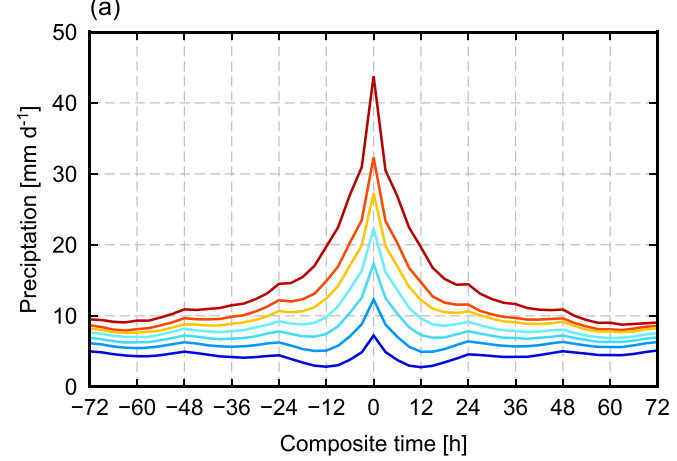

(c)

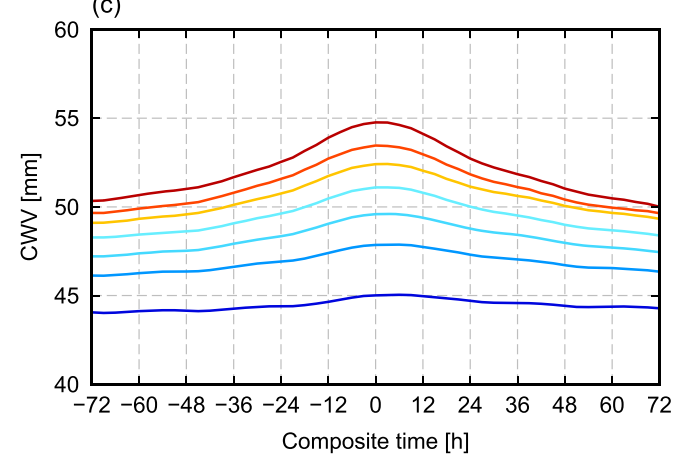

(b)

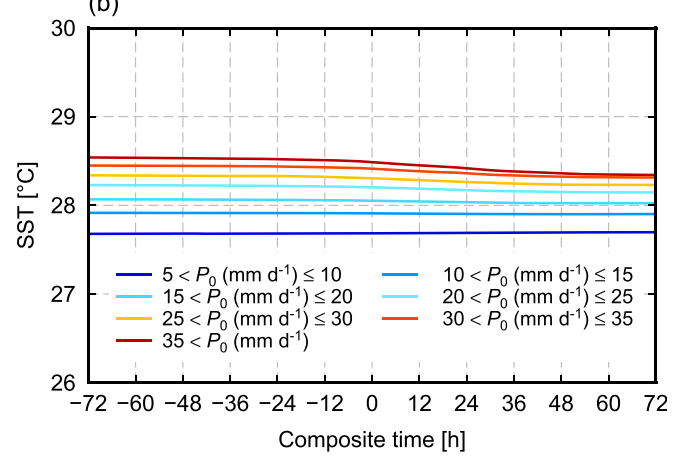

(d)

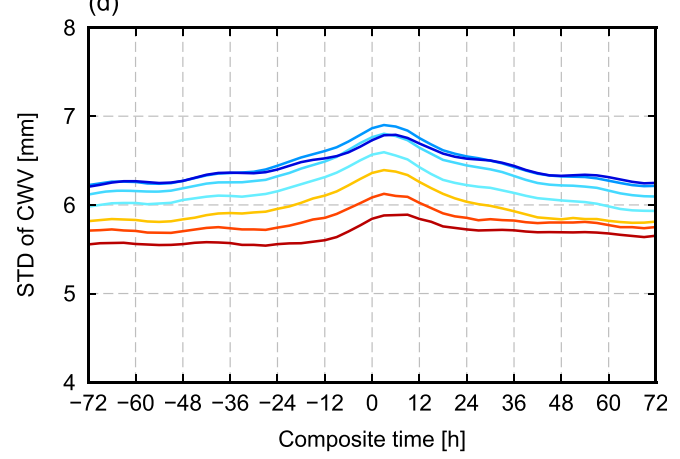

FIG. 1. Composite time series of (a) precipitation, (b) SST, (c) CWV, and (d) standard deviation of CWV within a $10^{\circ} \times 10^{\circ}$ domain. Composite curves separated by different $P_{0}$ regimes are plotted in different colors as indicated in the legend in (b). Time 0 refers to the hour when precipitation reaches a local maximum.

where a contraction of cloud cover is pronounced in anvil clouds, typically associated with deep cumulus towers (Stein et al. 2017). These studies present evidence that some key processes essential for simulated convective aggregation are at work in nature, whereas other aspects of self-aggregation specific to idealized model setups may not be directly comparable to observations. The aggregation time scale is among the latter, because it takes 15-100 days in RCE simulations for self-aggregation to develop from a perfectly disaggregated initial condition, which does not exist in nature (Holloway et al. 2017). In the real atmosphere, known tropical disturbances with a range of different lifetimes could be potential candidates for the real-world realization of convective aggregation, including tropical cyclones (e.g., Bretherton et al. 2005; Nolan et al. 2007; Khairoutdinov and Emanuel 2013) and the MJO (Arnold and Randall 2015; Khairoutdinov and Emanuel 2018). More short-lived systems such as cloud clusters, having a life cycle from subdaily to a few occurrences daily (Chen et al. 1996), have the tendency to be gregarious (Mapes 1993). It has not been explored in depth, however, to what extent such a short-term convective variability could be understood in the context of self-aggregation.

This paper analyzes satellite infrared measurements in search of the possible signals of convective aggregation (and disaggregation) in association with the life cycle of tropical cloud clusters. In the sections that follow, the term "selfaggregation" is reserved for the aforementioned physical phenomena explored in the literature, while temporal changes in the morphological characteristics of observed cloud clusters are described merely by aggregation or disaggregation. As such, the terms self-aggregation and aggregation have different nuances: the former refers to specific physical processes known from the literature and the latter is used for a description of observed features. Different metrics to quantify the degree of aggregation have been proposed such as the simple convective aggregation index (SCAI) (Tobin et al. 2012), the organization index or $I_{\mathrm{org}}$ (Tompkins and Semie 2017), the convective organization potential (COP) (White et al. 2018), and the morphological index of convective aggregation (MICA) (Kadoya and Masunaga 2018). The mutual consistency in performance among these indices has only very recently begun to be assessed (Pscheidt et al. 2019; Xu et al. 2019). We adopt SCAI in this study, as SCAI is the oldest of this kind and often regarded as the "standard" for a newer index to be compared against (White et al. 2018; Kadoya and Masunaga 2018). The physical nature of observed aggregation effects is studied from reanalysisbased energy budget considerations to seek the underlying physical processes as known for conventional self-aggregation in idealized simulations.

This article is structured as follows. Following a brief description of the datasets in section 2, possible signatures of short-range aggregation are sought in satellite observations (section 3) and an energy-budget analysis is performed in search of the key processes behind the observed signatures 

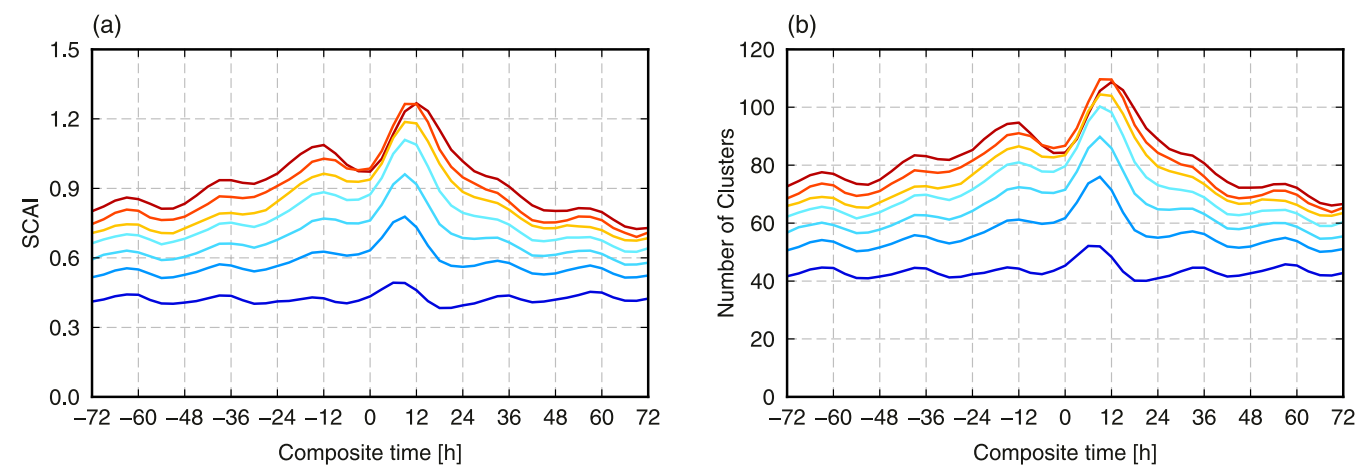

(c)
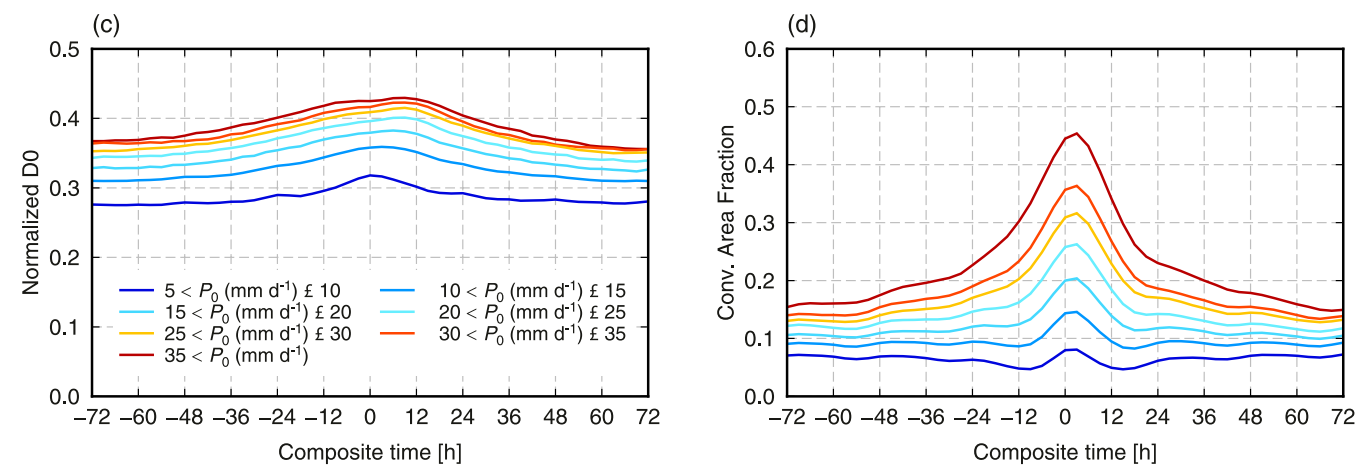

(e)
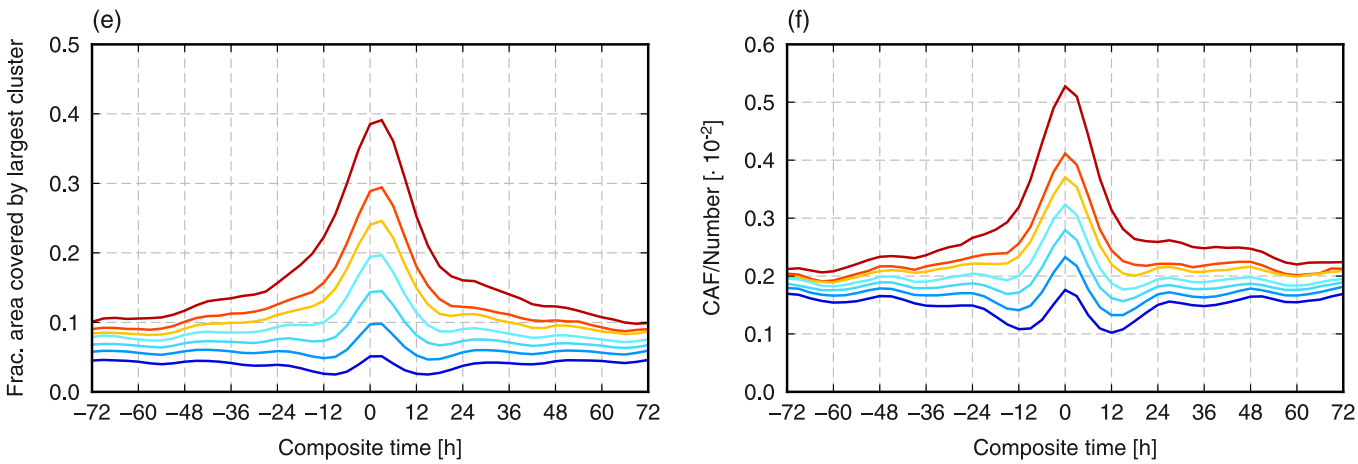

FIG. 2. As in Fig. 1, but for (a) SCAI, (b) the number of clusters, (c) normalized $D_{0}$, (d) convective area fraction,

(e) the area fraction of the largest cluster, and (f) convective area fraction divided by the number of clusters.

(section 4). The findings are summarized and discussed in section 5 .

\section{Data}

The input satellite observations for identifying cloud clusters are global imagery at a $4-\mathrm{km}$ resolution taken from the NOAA Climate Prediction Center (CPC) merged IR dataset (Janowiak et al. 2001). Cloud clusters are identified by a contiguous area of satellite pixels with window-channel IR brightness temperatures colder than $240 \mathrm{~K}$. We use 4-connectivity: this is what Tobin et al. (2012) used, and they found that results were not sensitive to using 8-connectivity instead (I. Tobin 2020, personal communication). Each $10^{\circ} \times 10^{\circ}$ domain, at each 3 hourly snapshot, is treated as if it were an independent scene. Cloud clusters that touch any domain boundary are counted the same as clusters that do not touch a boundary, and there is no attempt to connect clusters from one scene to another. For more details about the SCAI data (and related data), see section 2 of Stein et al. (2017), in which the same SCAI dataset was analyzed.

Convective area fraction $A_{c}$ is defined as the fractional area coverage of all cloud clusters together within a $10^{\circ} \times 10^{\circ}$ domain. SCAI, originally devised by Tobin et al. (2012), is defined as

$$
\mathrm{SCAI}=\frac{N_{c}}{N_{\max }} \frac{D_{0}}{L} \times 1000,
$$

where the first factor on the rhs is the number of cloud clusters $\left(N_{c}\right)$ normalized by a prescribed constant $\left(N_{\max }\right)$ to scale the magnitude of $N_{c}$, and the second is the geometrical mean of the distance between each pair of the cluster centroids $\left(D_{0}\right)$, 
(a) $29<\mathrm{SST}\left({ }^{\circ} \mathrm{C}\right)$

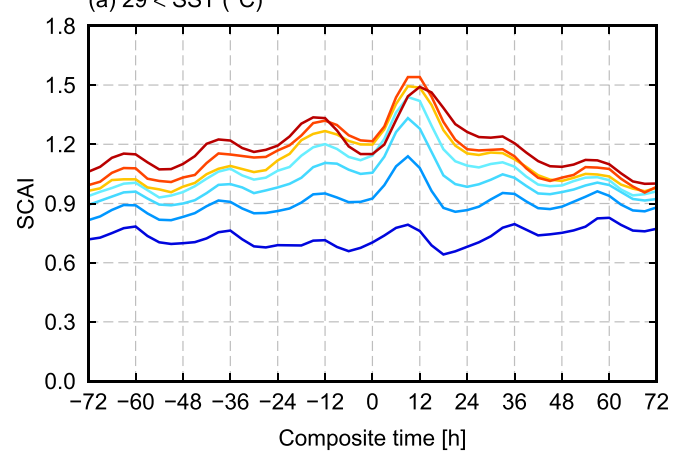

(c) $27<\mathrm{SST}\left({ }^{\circ} \mathrm{C}\right) \leq 28$

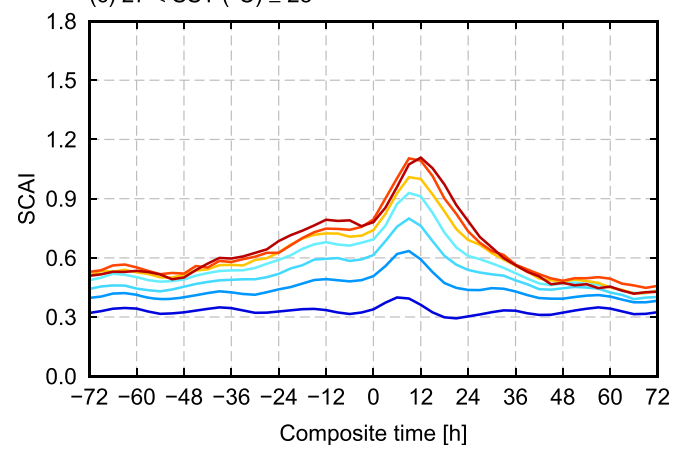

(b) $28<\mathrm{SST}\left({ }^{\circ} \mathrm{C}\right) \leq 29$

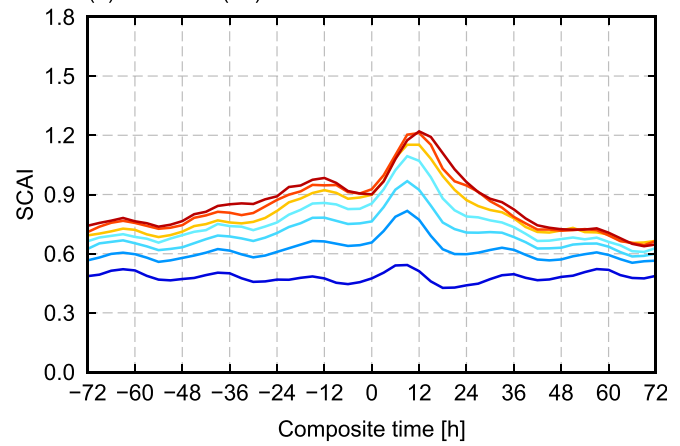

(d) $26<\mathrm{SST}\left({ }^{\circ} \mathrm{C}\right) \leq 27$

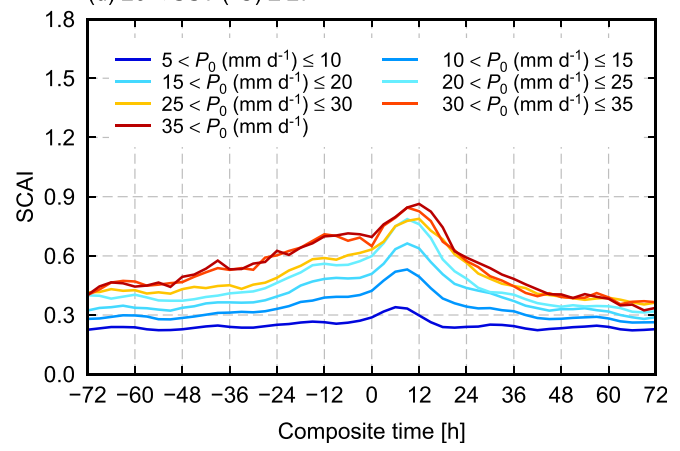

FIG. 3. Composite time series of SCAI stratified by different ranges of underlying SST at $t=0\left(\mathrm{SST}_{0}\right)$ as indicated by each panel.

normalized by the domain size $(L)$. As such, SCAI would decrease as cloud clusters are merged into fewer clusters (i.e., smaller $N_{c}$ ) that are more clumped together (i.e., smaller $D_{0}$ ) and therefore may be considered as an inverse measure of the degree of convective aggregation; that is, SCAI decreases as convection becomes more aggregated. In this work, SCAI is computed for every $10^{\circ} \times 10^{\circ}$ domain (hence $L=10^{\circ}$ ) with neighboring boxes overlapping each other by $5^{\circ}$, and $N_{\max }$ is chosen to be the largest possible value of $N_{c}$ or half the total pixel number within each box. SCAI is by design insensitive to some key aspects of convective aggregation that other proposed metrics explicitly rely on. The properties accounted for by other indices but not by SCAI include the area of cloud clusters in COP (White et al. 2018), randomness in the probability distribution of intercloud distance in $I_{\text {org }}$ (Tompkins and Semie 2017), and the spatial extent of cloud-free regions in MICA (Kadoya and Masunaga 2018). We nonetheless adopt SCAI in this study, taking advantage of its simplicity and hence of the ease of interpretation.

A variety of atmospheric and surface parameters, all averaged horizontally over the same $10^{\circ} \times 10^{\circ}$ domains as done for SCAI unless otherwise noted, are analyzed together with SCAI as outlined below. Three-hourly surface precipitation is obtained from the TRMM 3B42 product (Huffman et al. 2007). The SST data are from the $0.25^{\circ} \mathrm{TMI} / \mathrm{AMSRE}$ "fusion" (optimally interpolated) daily data (and the same value is repeated at each 3-h time during each day). This uses TMI microwavebased data (Wentz 2000), and since 2002 these data have been blended with AMSR-E microwave data using the optimal interpolation technique of Reynolds and Smith (1994). Column water vapor (CWV) is obtained from the ERA-Interim (ERAI) data (Dee et al. 2011). The ERAI datasets are also employed to provide a set of the parameters ingested into energy-budget analysis, that is, air temperature, vapor mixing ratio, geopotential height, horizontal and vertical winds, radiative heating rate, and surface heat fluxes. GridSat IR images (Knapp et al. 2011) are used for presenting sequential snapshots of cloud clusters in case studies.

All oceanic domains, from which any grid box partially covered with land is excluded, bound between $20^{\circ} \mathrm{S}$ and $20^{\circ} \mathrm{N}$ are included in the analysis for the 3.5-yr period from July 2006 to December 2009.

\section{Temporal evolution}

\section{a. Overview of composite time series}

The evolution of the atmospheric and surface states is first studied in terms of time series composited around a local peak in the Eulerian temporal sequence of precipitation. The local maxima of 3-hourly precipitation, averaged over a $10^{\circ} \times 10^{\circ}$ domain, are identified within a search window of $\pm 12 \mathrm{~h}$ in order to filter out short-term noise. The results were found insensitive to the window width when it is varied from \pm 6 to $\pm 24 \mathrm{~h}$ (not shown). The composite samples are broken down into seven precipitation regimes of $P_{0}<10,10-15,15-20$, 20-25, 25-30, 30-35, and $>35 \mathrm{~mm}$ day $^{-1}$, where $P_{0}$ denotes the 
(a)

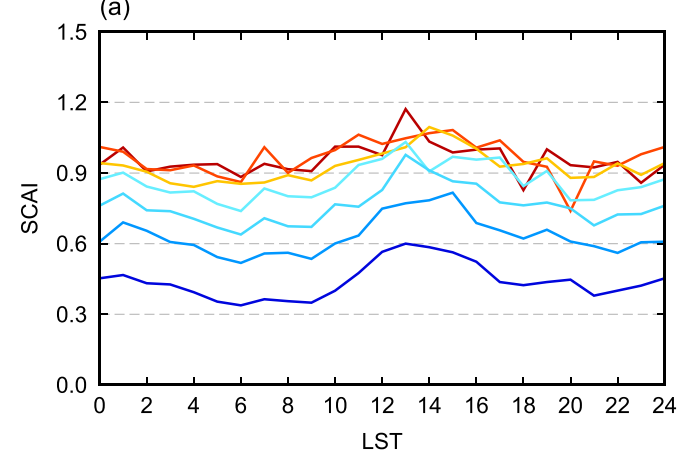

(c)

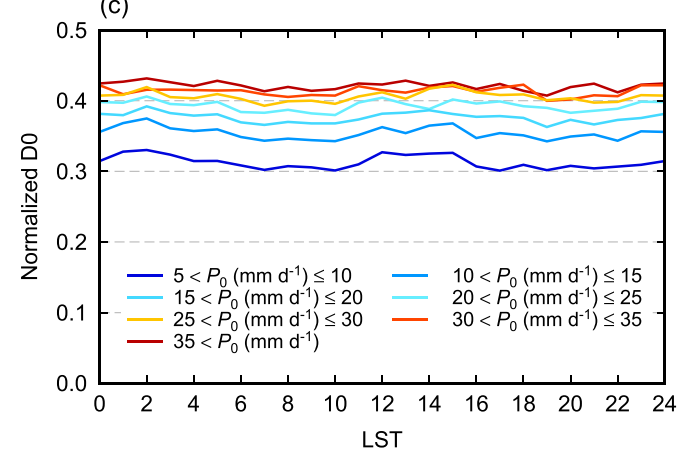

(b)

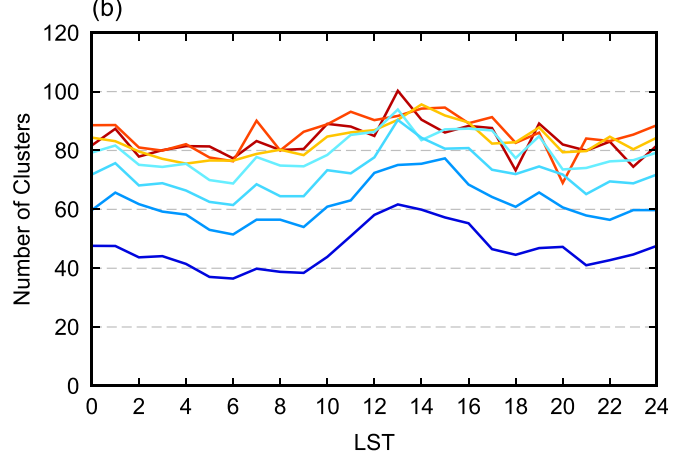

(d)

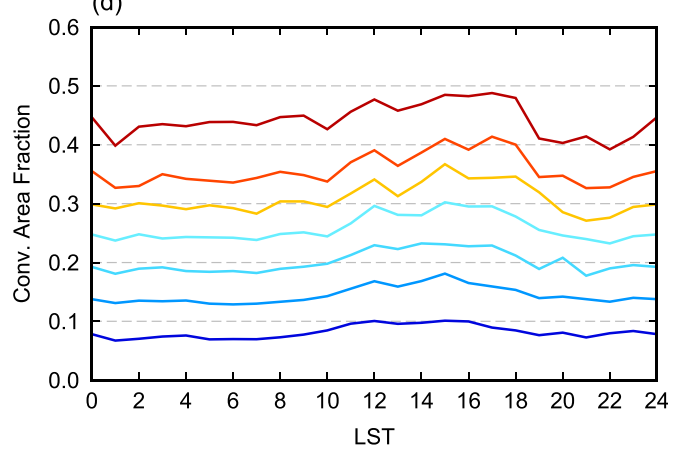

FIG. 4. The diurnal cycle of (a) SCAI, (b) the number of clusters, (c) normalized $D_{0}$, and (d) convective area fraction for different precipitation regimes.

domain-mean precipitation at the hour of the local precipitation maximum. The size of composite samples is summarized in appendix A. SCAI is meant to measure the degree of aggregation within each precipitation regime, making distinctions whether a given amount of precipitation is produced by heavily clustered clouds (i.e., more aggregated systems) or highly scattering convection (less aggregated). SCAI is not intended to be compared across different precipitation regimes.

Composite time series constructed in this simple Eulerian approach are potentially contaminated with spurious variability as convective disturbances enter and leave the study domain. Given that a typical migration speed of tropical cloud clusters is about $10 \mathrm{~m} \mathrm{~s}^{-1}$ (e.g., Nakazawa 1988), it takes roughly one day for convective disturbances to travel across a $10^{\circ} \times 10^{\circ}$ domain. Precipitation and cloud variability substantially longer than 1 day are likely affected by the appearance and disappearance of the disturbances through the domain boundaries, while more quickly varying signals, which are of main interest in this work as will become clear below, are explained mainly by the variability intrinsic of convective systems.

The composite time series of precipitation, SST, and CWV are shown for different precipitation regimes in Fig. 1. Precipitation has a striking peak at $t=0$ by construction, with its half-width at half maximum being roughly $12 \mathrm{~h}$. SST is nearly constant over time except for a subtle decrease after $t=0$ for large $P_{0}$ values. CWV has a maximum at $t=0$ but the variability around it is much less sharp than found for precipitation, as may be expected from the known nonlinear relationships between $P$ and $\mathrm{CWV}$ (Bretherton et al. 2004; Peters and Neelin 2006). The standard deviation of CWV within a $10^{\circ} \times 10^{\circ}$ domain has a modest enhancement similar to CWV itself, but a smaller $P_{0}$ is associated with a larger magnitude of the intradomain standard deviation of CWV. This may be because a modest precipitation peak is typically linked to a dry environment (Fig. 1c) and hence would not occur without an appreciable CWV variability with highly concentrated moist spots protecting precipitating clouds. The maximum of the CWV variability slightly lags the precipitation peak $(t=0)$. A possible explanation for this is that the stratiform component of organized cloud systems, having a tighter correlation with the ambient moisture than the convective component (Ahmed and Schumacher 2015), develops in a later stage of the convective life cycle.

Figure 2 presents SCAI and the related parameters. SCAI has a maximum slightly delayed (by $6-12 \mathrm{~h}$ ) behind precipitation. Diurnal modulation is also evident, as discussed later. For the largest values of $P_{0}$, SCAI temporarily reduces, showing signs of increased aggregation, while precipitation rapidly picks up during $\sim 12 \mathrm{~h}$ prior to time 0 and then increases back again until $t=12 \mathrm{~h}$. A decline of SCAI after its maximum for $t>0 \mathrm{~h}$ may result from the dissipation and/or disappearance of the disturbances through the observed domain boundaries as argued above, but the one before the peak is not intuitively obvious. Because SCAI is constituted of $N_{c}$ and $D_{0}$ as shown by (1), these two parameters are assessed individually in Figs. $2 \mathrm{~b}$ and $2 \mathrm{c}$. It is found that $N_{c}$ primarily accounts for the variability of SCAI while the role of $D_{0}$ is secondary, confirming the findings of Tobin et al. (2012). Convective area fraction, $A_{c}$, increases over time to its peak at $t=0$ with no trace of a temporary minimum as seen for SCAI (Fig. 2d). The evolution of $A_{c}$ is accounted for by 

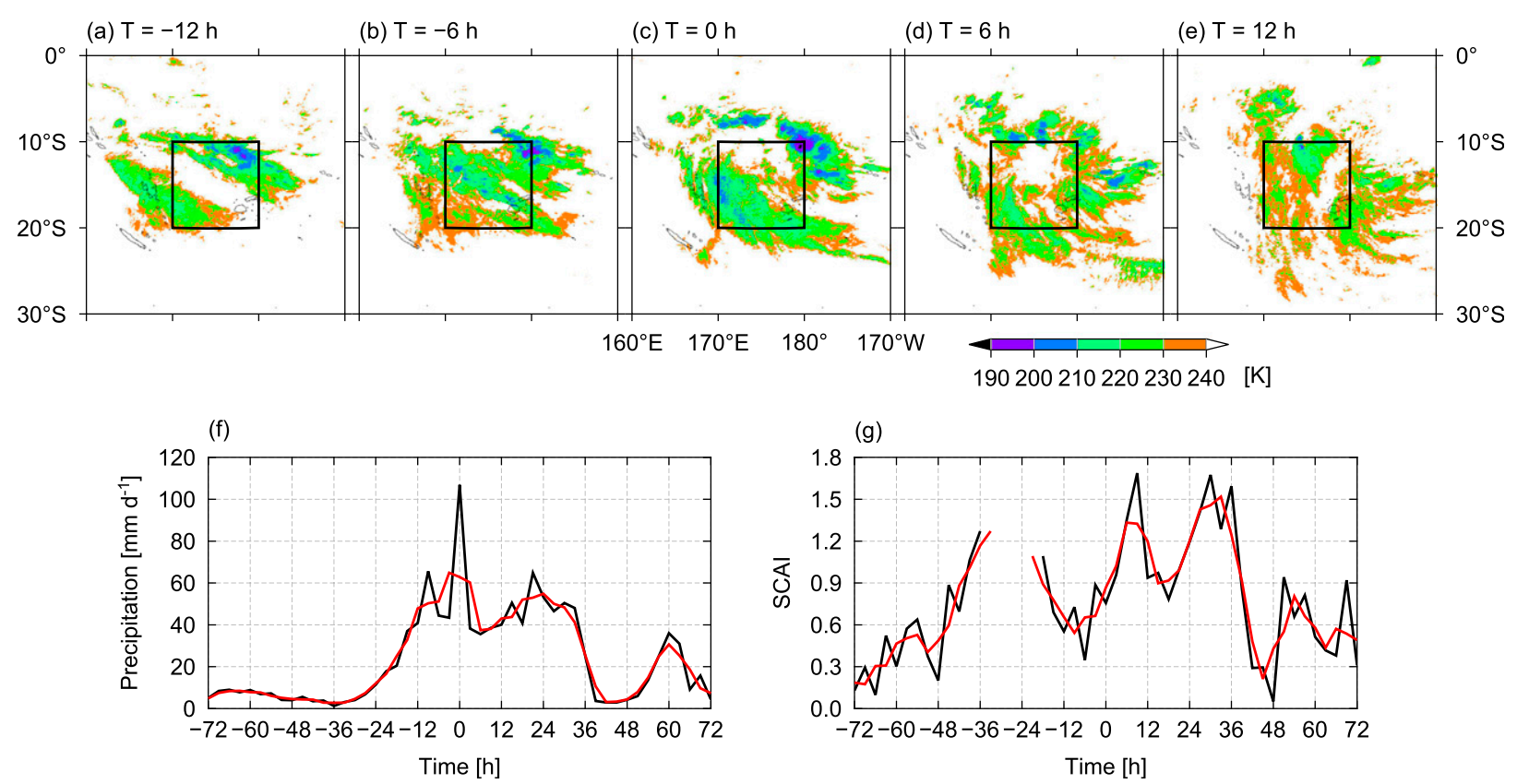

FIG. 5. (a)-(e) Plan views of infrared brightness temperature at selected hours of $-12,-6,0$, 6, and $12 \mathrm{~h}$, respectively, around $1500 \mathrm{UTC}$ $11 \mathrm{Jun} 2008$, at which the largest $P_{0}$ of $107 \mathrm{~mm} \mathrm{day}^{-1}$ is observed for the more-aggregated $\left(0.6<\mathrm{SCAI}_{0}<0.9\right)$ category. (f) The time series of precipitation averaged over a $10^{\circ} \times 10^{\circ}$ domain indicated by the black rectangle in (a)-(e). The three-point running mean of the original 3-hourly time series is shown in red. (g) As in (f), but for SCAI.

the spreading of high clouds around the time of peak convective activity, but the behavior of SCAI requires another explanation.

The dip of SCAI around $t=0$ for the heaviest precipitation regime is so shallow that it may not be interpreted with confidence as a proxy of aggregation without more supporting evidence. To aid in understanding this behavior of SCAI, Fig. 2e shows the cloud cover occupied by the largest cluster, which approaches a level very close to the total cloud fraction $A_{c}$ at $t=0$ (Fig. 2d). The high cloud cover therefore consists predominantly of a few largest clusters at the time of peak precipitation. In addition, the temporal change in the size distribution function of cloud clusters is evaluated in terms of the mean size of a cluster, that is, $A_{c}$ divided by $N_{c}$. This parameter represents the ratio of the first moment of the cluster size distribution function to its zeroth moment:

$$
\frac{A_{c}}{N_{c}}=\frac{n_{0} \int \sigma f(\sigma) d \sigma}{n_{0} \int f(\sigma) d \sigma}
$$

where $\sigma$ refers to the fractional area of clusters relative to the $10^{\circ} \times$ $10^{\circ}$ domain area, and $f(\sigma)$ is the normalized size distribution function with $n_{0}$ being its scaling factor. Note that $A_{c} / N_{c}$ varies only with the shape of the distribution function and is independent of $n_{0}$. Figure $2 \mathrm{f}$ shows that $A_{c} / N_{c}$ rises to the maximum at $t=0$ and then drops during a spell of $\pm 12 \mathrm{~h}$, resembling the behavior of the cloud cover occupied by the largest cluster. It is implied, given that $A_{c} / N_{c}$ would increase if $f(\sigma)$ shifts toward large sizes, that small cloud clusters gather into a few larger clusters as precipitation intensifies. This result appears to be in support of the hypothesis that a transient aggregation process is in progress as suggested by the behavior of SCAI.
When the composite SCAI is stratified by SST at $t=0$ or $\mathrm{SST}_{0}$ (Fig. 3), the major features found in Fig. 2 above are all present for $\mathrm{SST}_{0}>29^{\circ} \mathrm{C}$. The SCAI dip at $t=0$ and diurnal undulations become less clear as SST decreases and disappear for $\mathrm{SST}_{0}$ values below $27^{\circ} \mathrm{C}$.

The SCAI value at $t=0$, or hereafter $\mathrm{SCAI}_{0}$, is used to break down the composite evolution of SCAI for the purpose of highlighting differences in convective events with and without a noticeable sign of aggregation. Four SCAI ranges are chosen: $\mathrm{SCAI}_{0}>1.5$, $1.2 \leq \mathrm{SCAI}_{0} \leq 1.5,0.9 \leq \mathrm{SCAI}_{0} \leq 1.2$, and $0.6 \leq \mathrm{SCAI}_{0} \leq 0.9$, with the samples with $\mathrm{SCAI}_{0} \leq 0.6$ discarded. This choice of SCAI ranges preferentially samples warm ocean surfaces because SCAI generally exceeds 0.6 for SSTs higher than $28^{\circ} \mathrm{C}$ (Figs. 3a,b) while SCAI often falls below 0.6 for lower SSTs (Figs. 3c,d). Cold SSTs do not accompany the temporary aggregation (or the SCAI dip) are thus not of interest in the analysis that follows. The two contrasting cases of $\mathrm{SCAI}_{0}>1.5$ and $0.6<\mathrm{SCAI}_{0} \leq 0.9$ are defined as less-aggregated and more-aggregated cases, respectively, for the energy budget analysis presented in section 4.

\section{b. Effects of diurnal cycle}

A 24-h oscillation is clearly visible in the composite evolution of SCAI (Fig. 2), suggesting a possible influence of diurnal forcing. Figures $4 \mathrm{a}$ and $4 \mathrm{~b}$ show that SCAI and the number of clusters have an intrinsic diurnal cycle with an afternoon peak as discovered also by Doyle (2018) and Pscheidt et al. (2019). Its relevance to the diurnal cycle of precipitation is unclear, given that oceanic rainfall typically has an early-morning peak (e.g., Gray and Jacobson 1977). The amplitude of the diurnal cycle, largest for the lowest value of $P_{0}$, diminishes as 
(a) $\mathrm{T}=-12 \mathrm{~h}$

(b) $\mathrm{T}=-6 \mathrm{~h}$

(c) $\mathrm{T}=0 \mathrm{~h}$

(d) $\mathrm{T}=6 \mathrm{~h}$

(e) $\mathrm{T}=12 \mathrm{~h}$
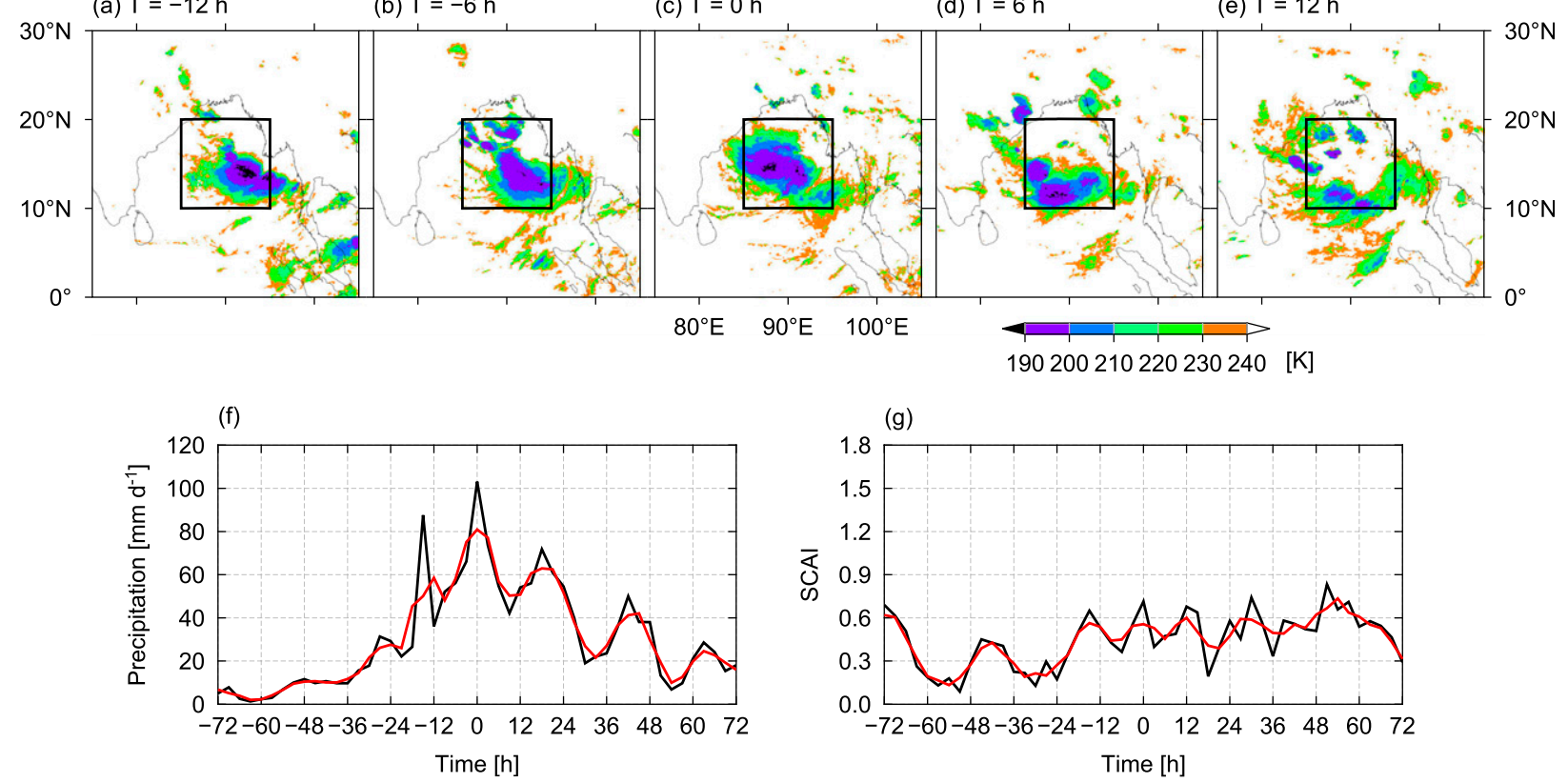

FIG. 6. As in Fig. 5, but for the second largest $P_{0}$ of $103 \mathrm{~mm} \mathrm{day}^{-1}$ (0900 UTC 4 Jun 2009).

$P_{0}$ increases. A possible reason is that heavily precipitating clouds are likely linked to the synoptic-scale dynamics beyond the control of the diurnal cycle, making a contrast to weak precipitation more susceptible to the local diurnal forcing. Diurnal variability is not pronounced for $D_{0}$ (Fig. 4c) and $A_{c}$ (Fig. 4d), except for a slight reduction of $A_{c}$ during 18-24 h. The day-night contrast in cloud-top temperature could potentially give rise to an artificial diurnal undulation in $A_{c}$ because a fixed infrared threshold of $240 \mathrm{~K}$ is applied uniformly over local time to define cloud clusters. The overall stability of $A_{c}$ found in Fig. $4 \mathrm{~d}$, however, suggests that this effect does not introduce any discernible diurnal bias.

Figure 4a suggests that diurnal cycle has little influence on SCAI for heavily precipitating systems. The transient aggregation within $\pm 12 \mathrm{~h}$ around a striking precipitation peak is thus unlikely controlled by the diurnal forcing. When the (a) $\mathrm{T}=-12 \mathrm{~h}$



(b) $\mathrm{T}=-6 \mathrm{~h}$

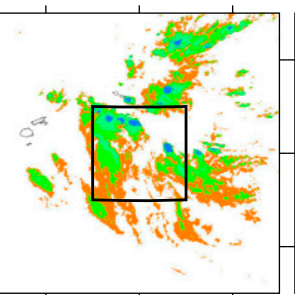

(c) $\mathrm{T}=0 \mathrm{~h}$

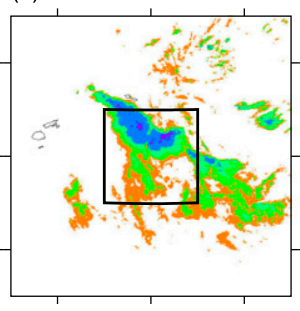

$180^{\circ}$ (d) $\mathrm{T}=6 \mathrm{~h}$

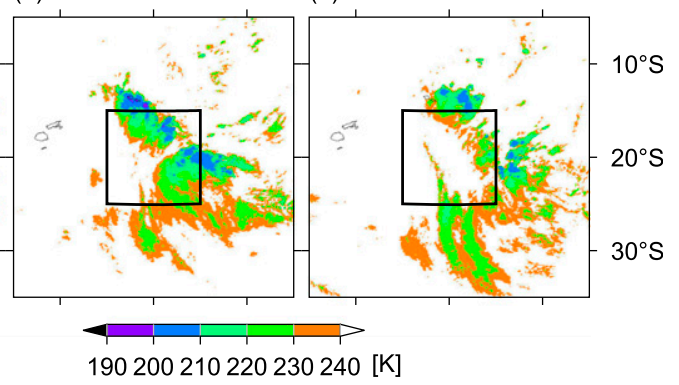

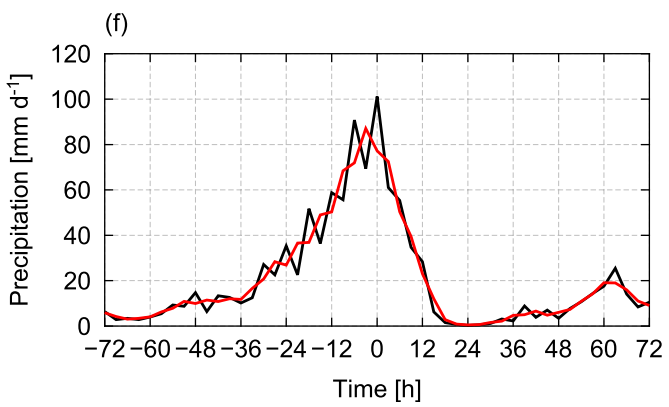

(g)

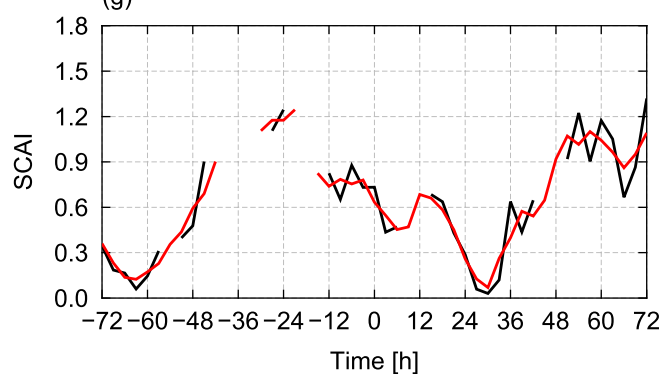

FIG. 7. As in Fig. 5, but for the third largest $P_{0}$ of $101 \mathrm{~mm} \mathrm{day}^{-1}$ (0900 UTC 7 Jun 2008). 
(a) $0.6<\mathrm{SCAl}_{0} \leq 0.9$

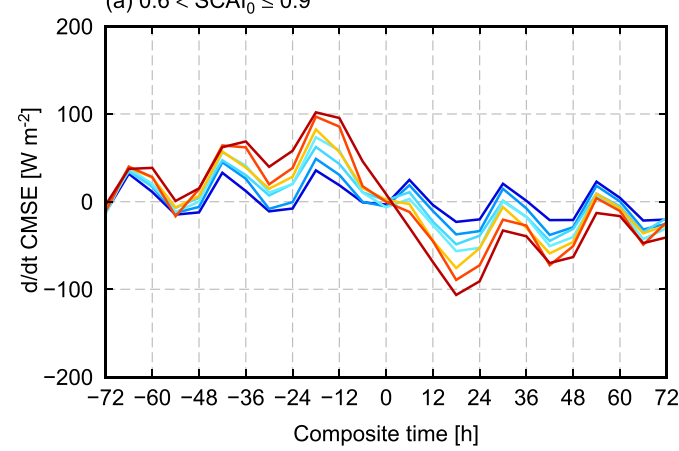

(c) $0.6<\mathrm{SCAl}_{0} \leq 0.9$

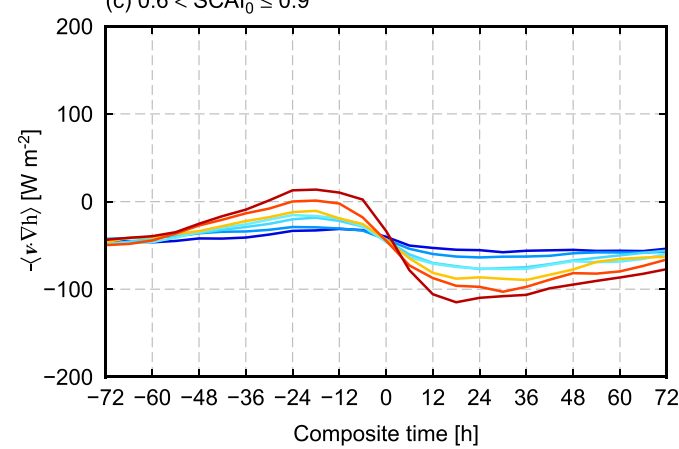

(e) $0.6<\mathrm{SCAl}_{0} \leq 0.9$

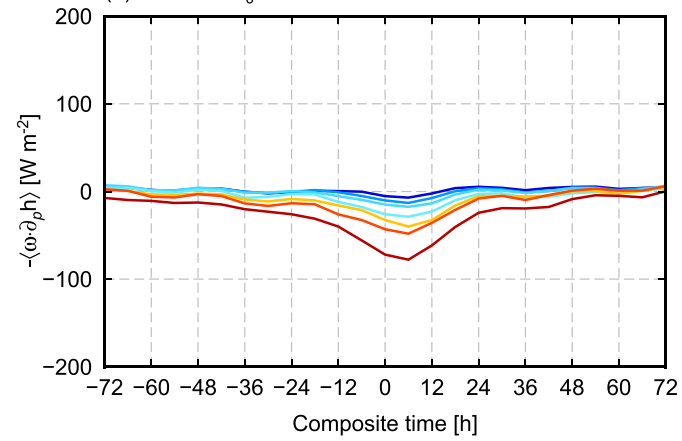

(b) $0.6<\mathrm{SCAl}_{0} \leq 0.9$

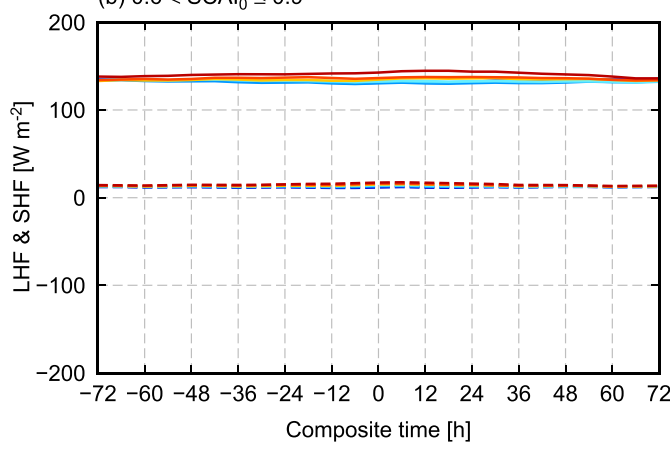

(d) $0.6<\mathrm{SCAl}_{0} \leq 0.9$

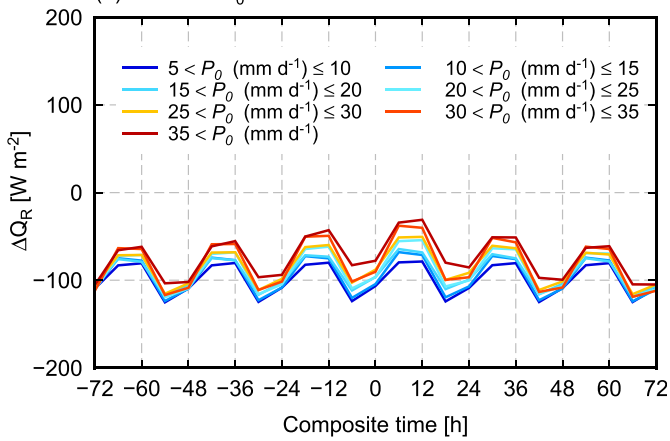

(f) $0.6<\mathrm{SCAI}_{0} \leq 0.9$



FIG. 8. Composite time series of the CMSE budget terms for the more-aggregated case $\left(0.6<\mathrm{SCAI}_{0}<0.9\right)$ : (a) the Eulerian MSE tendency, (b) latent heat flux (solid) and sensible heat flux (dashed), (c) horizontal MSE advection, (d) radiative heating rate, (e) vertical MSE advection, and (f) the budget residual.

composite SCAI is broken down by different local time at $t=0$ to further confirm this, SCAI, although having a distinct diurnal cycle that varies in phase among different local times, agree in that SCAI has a minimum near $t=0$ and hence the sign of the transient aggregation persists regardless of local time (see appendix B).

\section{c. Case study}

Are the temporary aggregation and the subsequent disaggregation visually recognized in individual convective events? A case study is conducted with three events having the first, second, and third largest values of $P_{0}$ among the samples with $0.6<\mathrm{SCAI}_{0}<$ 0.9. In the first event (Fig. 5), infrared imagery shows that two major cloud clusters at $-12 \mathrm{~h}$ (Fig. 5a) are merged into a larger cluster $6 \mathrm{~h}$ later (Fig. 5b) and then reach very cold cloud tops over a large area (Fig. 5c) before breaking up into smaller clusters with slightly warmer cloud tops (Figs. 5d,e). This observation from visual inspection may be qualitatively interpreted as a momentary aggregation toward $-6 \mathrm{~h}$, around which SCAI hits the minimum (Fig. 5g) despite the fact that precipitation then picks up (Fig. 5f). The second event is relatively stable over time in terms of SCAI (Fig. 6g), dominated by a single cloud cluster that is already in an aggregated state at $-12 \mathrm{~h}$ (Fig. 6a), which is slowly dissolved into multiple clusters by $12 \mathrm{~h}$ (Fig. 6e). A systematic evolution of SCAI is unclear within $\pm 12 \mathrm{~h}$ in this case although, given that SCAI stays as low as $\sim 0.3-0.6$, this particular case as a whole might be viewed as a prolonged period of an aggregated state. The last event (Fig. 7) exhibits a merger of multiple clusters into colder, larger, and fewer 


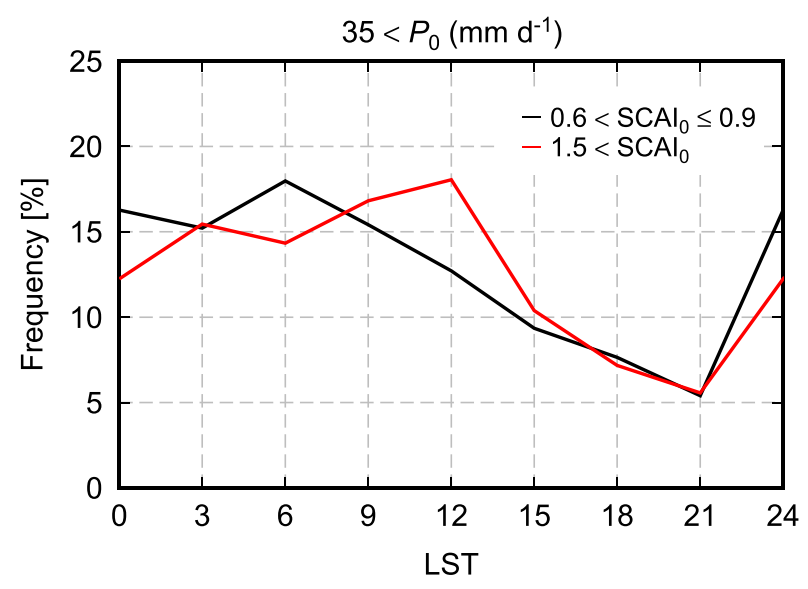

FIG. 9. A 3-hourly histogram of the precipitation peaks of $P_{0}>$ $35 \mathrm{~mm} \mathrm{day}^{-1}$ as a function of local time for the more-aggregated case $\left(0.6<\mathrm{SCAI}_{0}<0.9\right.$; in black $)$ and less-aggregated case $\left(\mathrm{SCAI}_{0}\right.$ $>1.5$; in red).

clusters until $0 \mathrm{~h}$ (Fig. 7c), followed by a separation of large cold clusters into smaller, warmer clusters, similarly to the first event. Note that cloud clusters begin to disperse out of the domain at $t=$ $12 \mathrm{~h}$ and as a result SCAI, closely related to the number of clusters, decreases to near zero at $t \approx 30 \mathrm{~h}$. This case raises a caveat that a reduction of SCAI should not be interpreted as a sign of aggregation when precipitation is virtually absent, in which case diminishing SCAI merely signifies the disappearance of clouds from the observed domain. In summary, at least two of the three events show a hint of aggregation as precipitation intensifies toward the peak, as may be expected from the composite ensemble. Aggregation is visible in the infrared imagery of individual events, but (at least for these cases and this methodology) it is far more modest and transient than a long-lasting aggregation process as seen in idealized simulations.

\section{Energy budget analysis}

\section{a. Temporal evolution}

It was found in the current observations that a sign of transient convective aggregation is present around the peak of heavy rainfall, although it is far more short-lived and subtle in magnitude than that seen in previous idealized numerical studies. Is the transient aggregation an entirely different entity from the well-known self-aggregation phenomena, or do they share any mechanisms at the process level? A useful strategy to pursue such potential similarities in the underlying physics is to compare the individual components of the moist static energy (MSE) budget in light of the processes known to be crucial for the self-aggregation such as moisture, radiation, and surface heat fluxes (see section 1). To this end, the MSE budget equation integrated over height,

$$
\left\langle\partial_{t} h\right\rangle=-\langle\mathbf{v} \cdot \nabla h\rangle-\left\langle\omega \partial_{p} h\right\rangle+L E+S+\left\langle Q_{R}\right\rangle+\varepsilon_{\mathrm{RA}},
$$

is analyzed, where angle brackets designate the vertical integral from the bottom to the top of the atmosphere, $\mathbf{v}$ is horizontal wind, $h$ is MSE, $L$ is the specific latent heat of vaporization, $E$ is the surface evaporation flux, $S$ is the surface sensible heat flux, $Q_{R}$ is the radiative heating rate, and $\varepsilon_{\mathrm{RA}}$ denotes the budget residual due to the reanalysis errors.

The $10^{\circ} \times 10^{\circ}$ domain mean of each term in (3) is first presented in the composite time series as shown in the previous section. The evolution for the more-aggregated composite $\left(0.6<\mathrm{SCAI}_{0}<0.9\right)$ is shown in Fig. 8. The composite time series of the column MSE (CMSE) tendency (Fig. 8a) undergoes a salient diurnal modulation, and otherwise the tendency mostly stays positive before the precipitation peak but is negative after the peak. The diurnal modulation is attributed to the solar cycle in the column radiative heating (Fig. 8d), which is not entirely averaged out in the composite statistics because of the inhomogeneous diurnal variability intrinsic to the precipitation-peak samples (Fig. 9). The dynamical terms such as the horizontal and vertical MSE advection, on the contrary, have little trace of the 24 -h cycle. The diurnal component of the MSE tendency is largely accounted for by the day-night radiative contrast, while the slowly varying component is almost exclusively attributed to the dynamical processes. The temporal asymmetry as found in the CMSE tendency is primarily brought about by the horizontal MSE advection (Fig. 8c) and, to a lesser extent, by unknown sources in the residual term (Fig. 8f). The horizontal MSE advection is overall negative except during limited hours prior to the precipitation peak for $P_{0}>35 \mathrm{~mm} \mathrm{day}^{-1}$, where the horizontal advection imports MSE. The horizontal MSE advection begins to enhance much earlier than precipitation (which sharply rises to the peak; Fig. 1a), indicating that a horizontal moisture gradient develops before convection develops. The vertical MSE advection stays always negative and reaches the minimum slightly after the precipitation peak (Fig. 8e), as expected from the invigoration of deep convection exporting MSE. The surface turbulent fluxes (Fig. 8b) are invariant over time and insensitive to $P_{0}$.

The less-aggregated composite is very similar to the moreaggregated case as illustrated above, except that the horizontal MSE advection enhances only modestly and never exceeds zero in the more-aggregated case even at its maximum (not shown).

\section{b. Internal variability}

Next examined is the horizontal variability of the MSE budget parameters. The budget terms, computed on the $0.75^{\circ} \times 0.75^{\circ}$ ERAI grid, are ordered by the magnitude of the column MSE within an encompassing large-scale $\left(10^{\circ} \times 10^{\circ}\right)$ domain. This procedure is repeated for all large-scale domains and averaged into the composite statistics sorted by the column MSE rank, following a convention of numerical work (Bretherton et al. 2005; Muller and Held 2012; Wing and Emanuel 2014; Muller and Bony 2015; Holloway and Woolnough 2016). Wing and Emanuel (2014) demonstrated the utility of variance-based MSE budget analysis for diagnosing the processes essential for convective aggregation, but this approach is not explored here because high-resolution data necessary to compute such variance are unavailable from the ERAI data. 




(c) $0.6<\mathrm{SCAl}_{0} \leq 0.9: 35<P_{0}\left(\mathrm{~mm} \mathrm{~d}^{-1}\right)$



(e) $0.6<\mathrm{SCAl}_{0} \leq 0.9: 35<P_{0}\left(\mathrm{~mm} \mathrm{~d}^{-1}\right)$

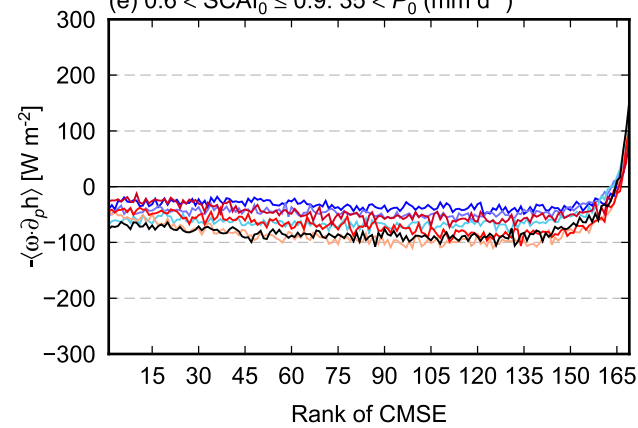

(b) $0.6<\mathrm{SCAl}_{0} \leq 0.9: 35<P_{0}\left(\mathrm{~mm} \mathrm{~d}^{-1}\right)$

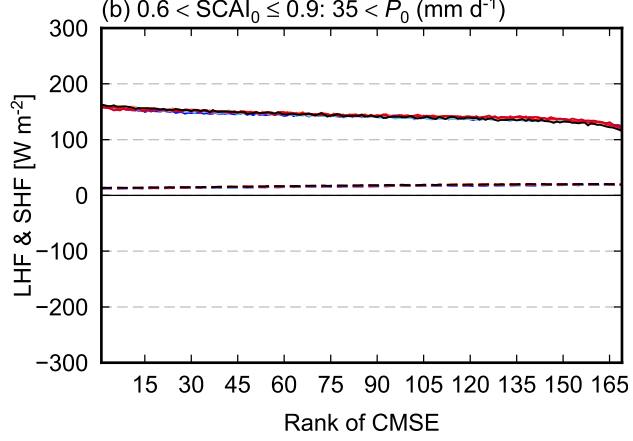

(d) $0.6<\mathrm{SCAl}_{0} \leq 0.9: 35<P_{0}\left(\mathrm{~mm} \mathrm{~d}^{-1}\right)$

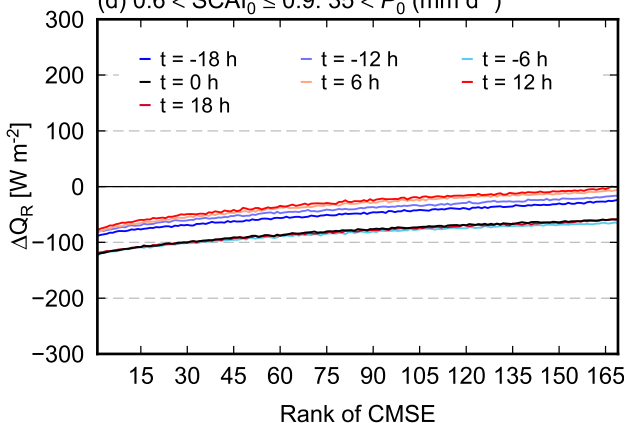

(f) $0.6<\mathrm{SCAl}_{0} \leq 0.9: 35<P_{0}\left(\mathrm{~mm} \mathrm{~d}^{-1}\right)$

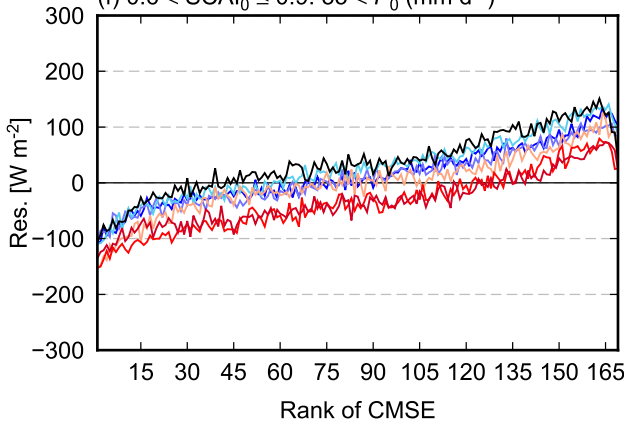

FIG. 10. The CMSE budget terms at selected hours, as indicated in the legend in (d), from the more-aggregated $\left(0.6<\mathrm{SCAI}_{0}<0.9\right)$ composite time series for $P_{0}>35 \mathrm{~mm}_{\text {day }}{ }^{-1}$ : (a) the Eulerian MSE tendency, (b) latent heat flux (solid) and sensible heat flux (dashed), (c) horizontal MSE advection, (d) radiative heating rate, (e) vertical MSE advection, and (f) the budget residual. The abscissa is the rank of column MSE ordered from the lowest to the highest.

Figure 10 presents the MSE budget breakdown for selected hours from the more aggregated $\left(0.6<\mathrm{SCAI}_{0}<0.9\right)$ composite time series. The CMSE tendency at $t=0$ (black curve in Fig. 10a) is negative for the lower half while positive for the upper half. Care must be taken, however, because the budget residual (Fig. 10f) implies a similar systematic bias of comparable magnitude and hence the CMSE tendency may be affected by reanalysis errors to a certain degree. The horizontal advection (Fig. 10c) is relatively homogeneous across the domain. The vertical advection (Fig. 10e) exports CMSE as seen earlier but sharply turns to positive in very moist columns. The latent heat flux (Fig. 10b) stays above $100 \mathrm{~W} \mathrm{~m}^{-2}$ with a slight decreases as CMSE increases. The sensible heat flux is minimal across all CMSE ranks. The radiative cooling becomes weaker (or approaches zero) with increasing MSE, likely because of increasing water vapor and high cloud cover from dry to moist columns. It is reminded that some of these features may be affected by systematic reanalysis errors as found in the residual bias.

The less-aggregated case is subtracted from the moreaggregated case next (Fig. 11) in order to focus on the difference between the two cases. It is also anticipated that $\varepsilon_{\mathrm{RA}}$ will be canceled out in the difference plots, assuming that the reanalysis errors are not correlated with the degree of convective aggregation. Figure 11 shows that, although the difference is overall small in magnitude (note that the vertical range spans $\pm 100 \mathrm{~W} \mathrm{~m}^{-2}$ here and $\pm 300 \mathrm{~W} \mathrm{~m}^{-2}$ in Fig. 10), the moreaggregated and less-aggregated composites are not entirely identical. The more-aggregated case is more efficient in column radiative cooling by more than $30 \mathrm{~W} \mathrm{~m}^{-2}$ at $t=0$. The CMSE tendency difference is overall attributable to the horizontal advection difference except for $t=0$ and $t=-18 \mathrm{~h}$, at 
(a) $35<P_{0}$ : $\left(0.6<\mathrm{SCAI}_{0} \leq 0.9\right)-\left(1.5<\mathrm{SCAI}_{0}\right)$

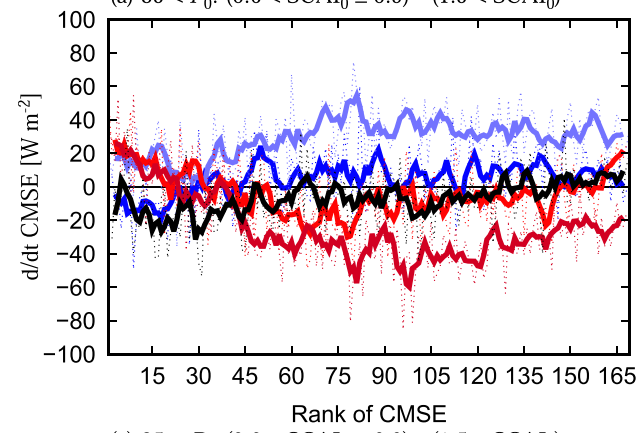

(c) $35<P_{0}$ : $\left(0.6<\mathrm{SCAI}_{0} \leq 0.9\right)-\left(1.5<\mathrm{SCAI}_{0}\right)$

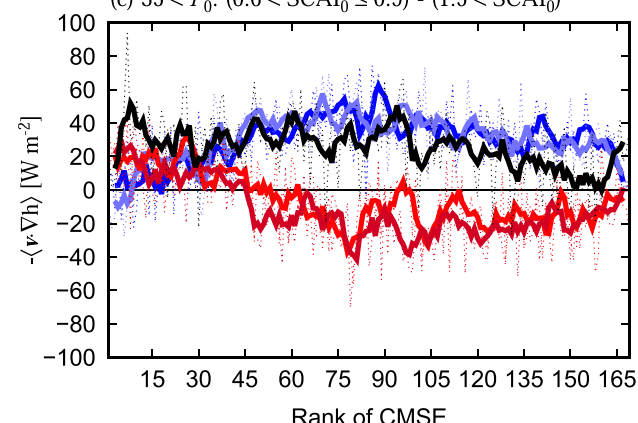

(e) $35<P_{0}:\left(0.6<\mathrm{SCAI}_{0} \leq 0.9\right)-\left(1.5<\mathrm{SCAI}_{0}\right)$

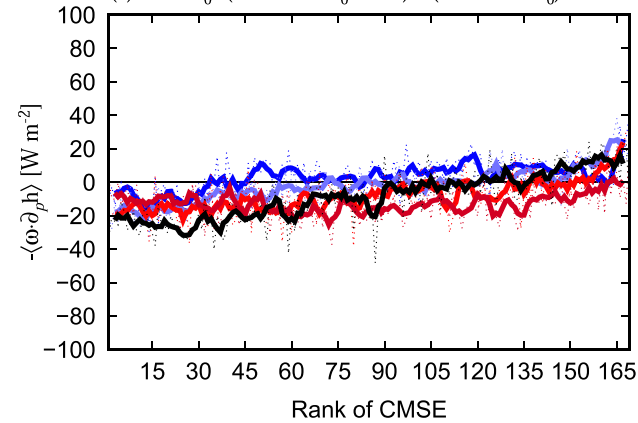

(b) $35<P_{0}:\left(0.6<\mathrm{SCAI}_{0} \leq 0.9\right)-\left(1.5<\mathrm{SCAI}_{0}\right)$

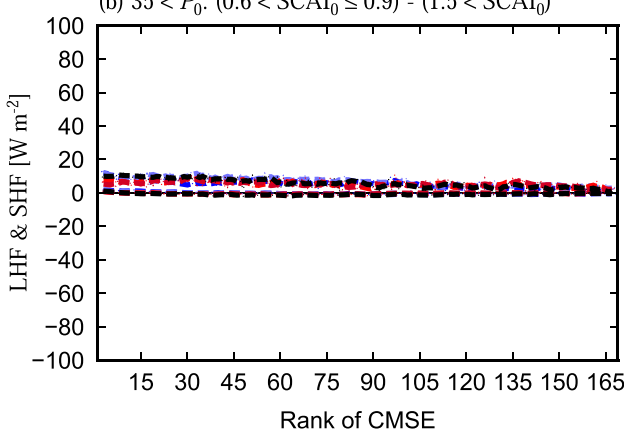

(d) $35<P_{0}:\left(0.6<\mathrm{SCAI}_{0} \leq 0.9\right)-\left(1.5<\mathrm{SCAI}_{0}\right)$

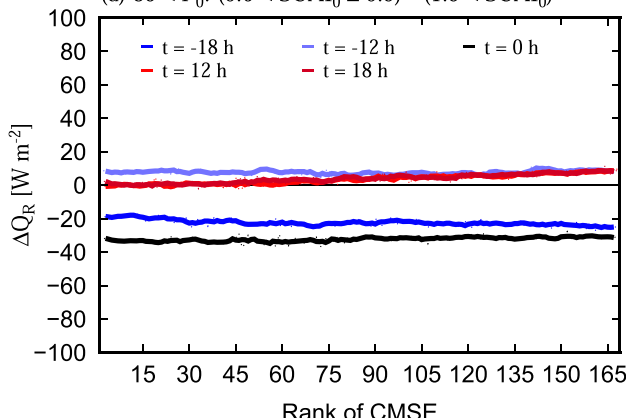

(f) $35<P_{0}$ : $\left(0.6<\mathrm{SCAI}_{0} \leq 0.9\right)-\left(1.5<\mathrm{SCAI}_{0}\right)$

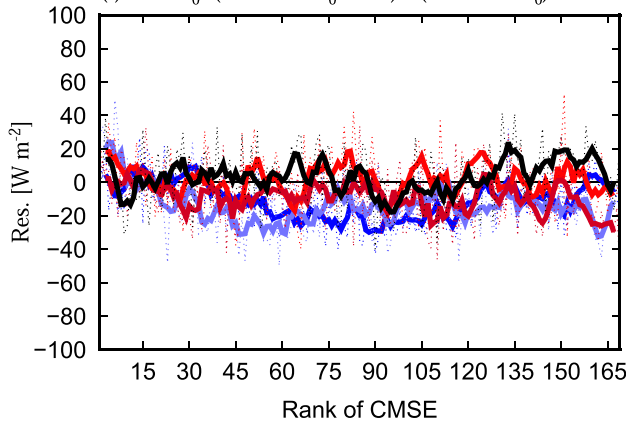

FIG. 11. As in Fig. 10, but for the difference between the more-aggregated case $\left(0.6<\mathrm{SCAI}_{0}<0.9\right)$ minus the less-aggregated $\left(\mathrm{SCAI}_{0}>1.5\right)$. Thick solid lines are the five-point running mean applied to the original curves (thin dashed). Only three time slices at \pm 12 and $0 \mathrm{~h}$ are shown for visual clarity.

which time a positive difference in the horizontal advection is largely offset by a negative difference in $Q_{R}$ and hence the CMSE tendency difference stays near zero. A closer examination reveals that the CMSE tendency difference at $t=0$ (black) has a slight positive gradient extending from almost the lowest MSE rank to the highest. This gradient, accounted for by the vertical advection difference, implies that the columns with low CMSEs continue to lose further CMSE while the high-CMSE columns maintain or even gain more CMSE. Such an upgradient transport of CMSE works somewhat more efficiently in more-aggregated events than in less-aggregated events, although the difference is so subtle that this remains speculative without further evidence. The difference in $\varepsilon_{\mathrm{RA}}$ suffers little systematic bias, so the more-aggregated versus less-aggregated differences turn out to be less subject to the reanalysis errors than each individual composite.

\section{Discussion and summary}

In this paper, possible signs of convective aggregation are explored in satellite observations and reanalysis datasets. The time scales of present interest are a few days or shorter instead of 15-100 days as seen in RCE simulations in order to seek the aggregation signatures intrinsic to the life cycle of organized convective systems. The composite time series of various parameters, all averaged over $10^{\circ} \times 10^{\circ}$ domains, are built around a local maximum of precipitation $\left(P_{0}\right)$ as a statistical representative of the convective life cycle. The composite samples are stratified by seven precipitation regimes from the lightest $\left(5<P_{0} \leq 10 \mathrm{~mm} \mathrm{day}^{-1}\right)$ to the heaviest $\left(P_{0}>\right.$ $35 \mathrm{~mm} \mathrm{day}^{-1}$ ) categories.

The composite evolution exhibits a momentary decline of SCAI as precipitation picks up and the high-cloud cover 

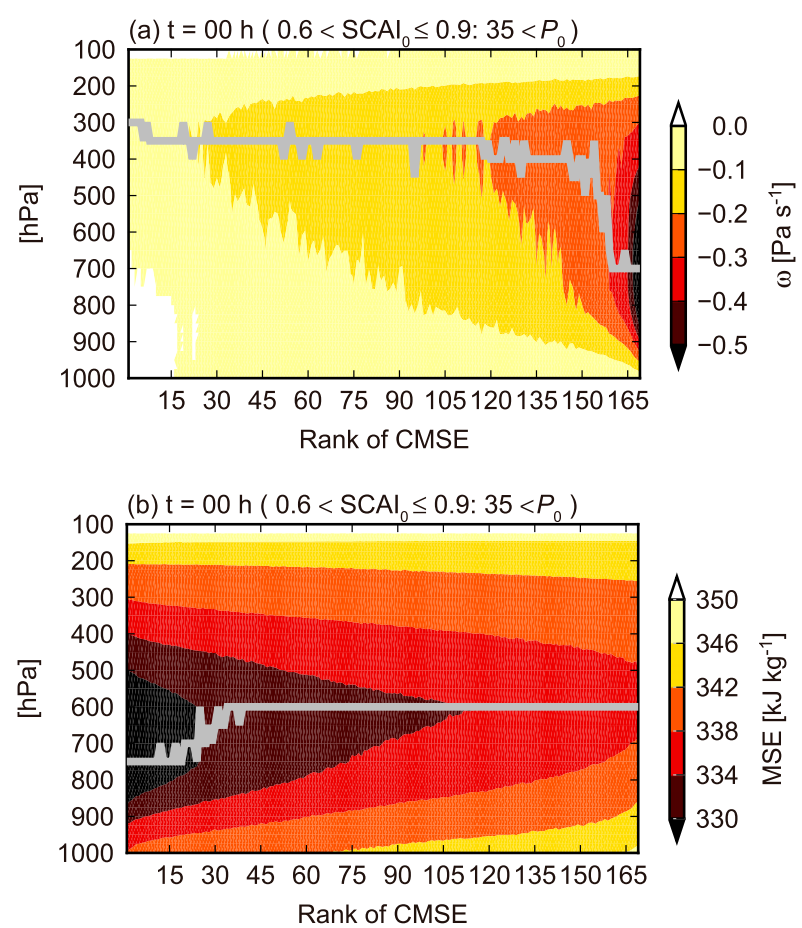

FIG. 12. The $10^{\circ} \times 10^{\circ}$ mean (a) $\omega$ and (b) MSE as a function of the MSE rank from the more aggregated $\left(0.6<\mathrm{SCAI}_{0}<0.9\right)$ composite at $t=0$ for $P_{0}>35 \mathrm{~mm} \mathrm{day}^{-1}$. The height of the maximum ascent and the minimum MSE is traced in gray in (a) and (b), respectively.

expands to their peak. This decrease of SCAI accompanies a modest shift in the histogram of cloud clusters so that small cloud clusters are merged into fewer and larger clusters, suggesting a transient occurrence of convective aggregation. The duration time of this aggregation effect is 1 day or shorter, and the degree to which aggregation proceeds, as visually recognized from a case study, is rather limited. The sign of the transient aggregation in the composite evolution of SCAI is salient in the heaviest precipitation regime, but becomes fainter as $P_{0}$ decreases.

The time scale of the observed transient aggregation process is substantially smaller than the known time scales of 15100 days from idealized simulations (Wing et al. 2017). The discrepancy in time scale, however, may not necessarily imply that the short-term aggregation in the current observations is entirely irrelevant to what we have learned from past numerical simulations. The key feedback processes crucial for aggregation as identified in idealized simulations are at work in more realistic simulations as well (Holloway 2017), while the aggregation time scales in RCE simulations initiated with a homogeneous field have little direct relevance to the real world (Holloway et al. 2017). The real atmosphere never experiences a uniform, disaggregated state to start with, and a $10^{\circ} \times 10^{\circ}$ domain in nature is exposed constantly to external synoptic-scale disturbances, potentially destroying an environment favorable for the continuous development of aggregation. On the other hand, this transient aggregation may
TABLE A1. The number of samples (at $t=0$ ) stratified by precipitation. The unit is $\mathrm{mm} \mathrm{day}^{-1}$ for precipitation.

\begin{tabular}{lc}
\hline \hline Precipitation & No. of peaks \\
\hline $35<P$ & 6217 \\
$30<P \leq 35$ & 4505 \\
$25<P \leq 30$ & 7423 \\
$20<P \leq 25$ & 12145 \\
$15<P \leq 20$ & 19348 \\
$10<P \leq 15$ & 31930 \\
$5<P \leq 10$ & 56247 \\
\hline
\end{tabular}

possibly be relevant to the gregarious nature of tropical cloud clusters as found in satellite imagery by Mapes (1993), who proposed a theory that the gravity wave propagation triggered by initial convection generates a thermodynamic state favorable for subsequent convection in close vicinity. The time scale of this mechanism is several hours, comparable to the aggregation time found in this work.

The transient form of convective aggregation is detectable only over warm oceans ( $\mathrm{SST}>28^{\circ} \mathrm{C}$ ), which appears to confirm some existing numerical studies (Wing and Emanuel 2014) although the sensitivity to SST is still in dispute (Coppin and Bony 2015; Wing and Cronin 2016; Holloway and Woolnough 2016). SST tends to be higher for a larger $P_{0}$ but somewhat decreases with time as precipitation decays after its peak, ascribable to multiple possibilities including the high-cloud shielding of insolation (Wall et al. 2018) and the enhanced surface heat flux following a spell of active convection (Young et al. 1995). This also resembles the evolution of convective aggregation in a coupled model where convection chases after a warmer ocean until it finds itself over the warmest spot and eventually dies out (Coppin and Bony 2017).

Diurnal modulation is evident in the temporal evolution of SCAI because the SCAI itself has a diurnal variation and the composite samples are not entirely homogeneously distributed over local time. The diurnal peak of SCAI lies in the afternoon, nearly half a day out of phase from the diurnal cycle of precipitation for unknown reasons over tropical oceans. Precipitation and SCAI, on the contrary, are nearly in phase over tropical continents, both having a distinct afternoon peak (Doyle 2018). It is noted that the diurnal cycle of cold cloud fraction varies with the infrared threshold, where the local time of the peak moves forward from around noon to 0600 or earlier as the threshold is lowered from 235 to $215 \mathrm{~K}$ (Janowiak et al. 1994). The afternoon maximum of SCAI therefore may be peculiar to a relatively warm threshold of $240 \mathrm{~K}$ as currently chosen, and a colder threshold could make the diurnal peak shift closer to that of precipitation. In any case, the transient aggregation is not merely an aliasing effect of the diurnal cycle, given that the temporal minimum of SCAI around $t=0$ persists regardless of local time when the composite time series are subsampled by different local hours.

There is no evidence indicating that the latent and sensible heat fluxes make any significant contribution to the transient aggregation, given that the more-aggregated $\left(0.3<\mathrm{SCAI}_{0} \leq\right.$ $0.6)$ and less-aggregated $\left(\mathrm{SCAI}_{0}>1.5\right)$ composites are nearly 
TABLE A2. The number of samples (at $t=0$ ) stratified by precipitation and SST. The unit is mm day ${ }^{-1}$ for $P$ and ${ }^{\circ} \mathrm{C}$ for SST.

\begin{tabular}{lccrr}
\hline \hline Precipitation & $29<\mathrm{SST}$ & $28<\mathrm{SST} \leq 29$ & $27<\mathrm{SST} \leq 28$ & $26<\mathrm{SST} \leq 27$ \\
\hline $35<P$ & 2479 & 1828 & 718 & 348 \\
$30<P \leq 35$ & 1602 & 1471 & 693 & 237 \\
$25<P \leq 30$ & 2327 & 2458 & 1333 & 465 \\
$20<P \leq 25$ & 3472 & 3925 & 2421 & 930 \\
$15<P \leq 20$ & 4735 & 6006 & 4311 & 7887 \\
$10<P \leq 15$ & 6833 & 9458 & 1354 & 3848 \\
$5<P \leq 10$ & 9713 & 15381 & 1320 & 8249 \\
\hline
\end{tabular}

identical in the surface fluxes (Fig. 11b). This is consistent with previous idealized studies showing that, while surface fluxes can be important for initiation of self-aggregation, they are not important for its maintenance (Holloway and Woolnough 2016).

The diurnal cycle of radiative cooling is similar in magnitude but not identical in phase between the more-aggregated and the less-aggregated composites. As a result, the moreaggregated case has a radiative cooling that is more than $30 \mathrm{~W} \mathrm{~m}^{-2}$ stronger at $t=0$ than the less-aggregated case. It follows that the large-scale atmosphere including a developing convective system may experience a distinct radiative cooling during the transient aggregation. It is unclear, however, to what extent this enhanced radiative cooling corroborates the convective-radiative feedback important for convective selfaggregation in idealized numerical simulations (Wing et al. 2017, and references therein). The difference in $Q_{R}$ between the more- and less-aggregated composites has little systematic dependence on the column MSE (Fig. 11). A potential radiative feedback implied by the $Q_{R}$ dependence on CMSE for the more-aggregated composite (Fig. 10d) is hence not discernibly stronger than for the less-aggregated case. The lack of evidence for any distinct effect of $Q_{R}$ on the aggregation may be understood in the context of the scale dependence of the aggregation processes. Beucler and Cronin (2019) and Beucler et al. (2019) showed that the longwave effects favor a growth of large-scale aggregation with horizontal wavelengths of $\sim 1000 \mathrm{~km}$ or larger, which exceeds the typical size of cloud clusters studied in the current analysis. Shortwave radiation, on the other hand, has the effect of shrinking the aggregation to smaller scales (500-2000 km) (Beucler and Cronin 2019). This has a possible link to the diurnal maximum of disaggregation at afternoon hours (Fig. 4a).

The horizontal MSE advection is overall negative, suggesting that the domain of interest may be incessantly exposed to an intrusion of relatively dry ambient air. This hypothesis is not unrealistic, given that the composite time series are constructed around a precipitation maximum and hence the domain of interest is likely moister than the surroundings. The horizontal MSE advection exhibits a positive anomaly hours before the peak precipitation and a negative anomaly after with their amplitude more pronounced for more intense precipitation. This pair of anomalies with opposite signs implies the development of a horizontal moisture gradient prior to the intensification of convection and the dissipation of the moisture gradient as the convection dies out. The positive anomaly prior to the rainfall peak is a primary driver of the enhanced CMSE tendency, especially for the moreaggregated case. It is suggested that the horizontal advection has the potential to help the moist air further moisten with the possibility to boost a new convective burst. This effect, if it exists, may be related to the moisture-memory feedback as often discussed in attempt to interpret convective self-aggregation in numerical simulations (Held et al. 1993; Tompkins 2001; Muller and Bony 2015). The importance of the advection term in the CMSE budget is in line with Bretherton and Khairoutdinov (2015), who showed that the advection accounts for the rapid ( $<4$ days) growth of MSE at the earliest stage of aggregation, although at odds with Beucler et al. (2019), who found that the advection damps the MSE variance at all spatial scales.

The vertical MSE advection sharply rises to above zero for columns with the largest MSEs. The reason for this is illustrated in Fig. 12a, where the vertical structure of $\omega$ transitions abruptly from a top-heavy profile to a bottom-heavy one at around the 150th rank (out of the $\sim 170$ columns in total). This feature in theory activates an upgradient transport of CMSE, an element known as critical for aggregation (Bretherton et al. 2005; Muller and Held 2012; Muller and Bony 2015), since a bottom-heavy updraft imports lower-tropospheric MSE more than it exports MSE at higher levels and hence enhances CMSE. One should bear in mind that $\omega$ profiles from reanalysis data may be sensitive to the parameterization uncertainties,

TABLE A3. The number of samples (at $t=0$ ) stratified by precipitation and SCAI. The unit is mm day ${ }^{-1}$ for precipitation.

\begin{tabular}{cccrc}
\hline \hline Precipitation & $1.5<\mathrm{SCAI}$ & $1.2<\mathrm{SCAI} \leq 1.5$ & $0.9<\mathrm{SCAI} \leq 1.2$ & $0.6<\mathrm{SCAI} \leq 0.9$ \\
\hline $35<P$ & 810 & 782 & 1185 & 1519 \\
$30<P \leq 35$ & 683 & 552 & 861 & 1036 \\
$25<P \leq 30$ & 1022 & 869 & 1277 & 1616 \\
$20<P \leq 25$ & 1442 & 1188 & 1950 & 2679 \\
$15<P \leq 20$ & 1663 & 1539 & 2697 & 4151 \\
$10<P \leq 15$ & 1899 & 1797 & 3265 & 6042 \\
$5<P \leq 10$ & 1491 & 1642 & 3394 & 6997 \\
\hline
\end{tabular}


(a) $35<P_{0}\left(\mathrm{~mm} \mathrm{~d}^{-1}\right)$

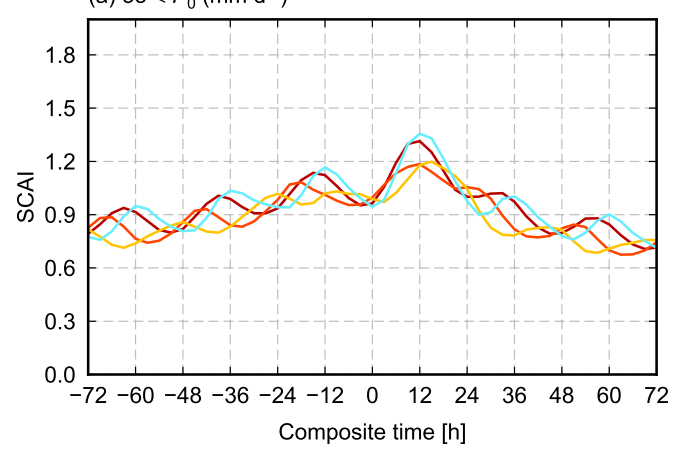

(c) $35<P_{0}\left(\mathrm{~mm} \mathrm{~d}^{-1}\right)$

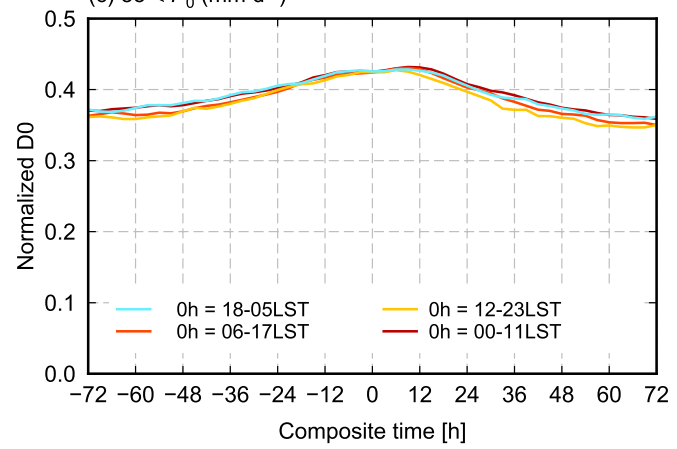

(b) $35<P_{0}\left(\mathrm{~mm} \mathrm{~d}^{-1}\right)$

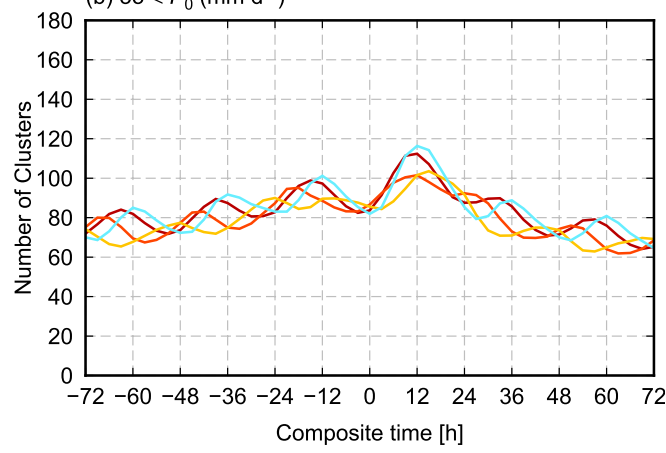

(d) $35<P_{0}\left(\mathrm{~mm} \mathrm{~d}^{-1}\right)$

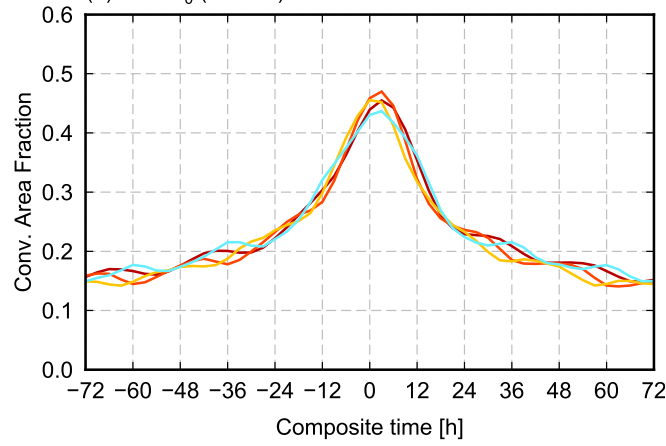

FIG. B1. As in Fig. 2, but broken down by local time at $t=0$ into four 12-h windows (with 6-h overlaps). All curves are conditioned by $P_{0}>35 \mathrm{~mm}$ day $^{-1}$.

and the robustness of this result has yet to be confirmed. The minimum in the vertical MSE profiles is somewhat low in altitude for the lowest-CMSE columns, while it stays invariant across the highest-CMSE columns (Fig. 12b). The sudden transition in the vertical MSE advection for the moistest columns is therefore solely ascribed to the aforementioned change in the vertical structure of $\omega$.

The transience of the aggregation processes in the observations may be partly due to limitations of the present analysis strategy. The composite time series by design represent the Eulerian evolution within a $10^{\circ} \times 10^{\circ}$ domain. This practically limits the time scale of interest because convective disturbances rarely stay at the same location over an extended period of time beyond $\sim 1$ day. The utility of the Lagrangian analysis would be worth pursuing in future work to overcome the current technical limitations, although a Lagrangian analysis with a cloud tracking algorithm has its own technical challenges including how to deal with the merging and splitting of cloud clusters. The Eulerian and Lagrangian approaches each have strengths and drawbacks that are complementary by nature.

Slowly evolving convective aggregation, if it exists in nature, should be sought in a significantly larger domain than we currently analyzed. It is noted, on the other hand, that past numerical work found convective self-aggregation to occur in a computational domain with a size comparable to or even smaller than a $10^{\circ} \times 10^{\circ}$ square. Signs of the transient aggregation might emerge in numerical simulations as well when the long-term variability is filtered out, although this has so far not received much attention to in the literature.

Acknowledgments. We thank three anonymous reviewers for their comments, which helped us enrich the discussion and improve the presentation. H. Masunaga is supported by Japan Society for the Promotion of Science (JSPS) Grants-in-Aid for Scientific Research (KAKENHI) 19H01966. The GridSat data were obtained from NOAA (www.ncdc.noaa.gov/gridsat/) and the ERAI data were provided by ECMWF (apps.ecmwf.int/ datasets/). The combined dataset including SCAI and its ancillary parameters was created using funding from U.K. NERC Grant $\mathrm{NE} / \mathrm{I} 021012 / 1$ and is available through the NERC Centre for Environmental Data Archival (CEDA) (catalogue.ceda.ac.uk).

\section{APPENDIX A}

\section{Sample Size in the Composite Statistics}

Tables A1-A3 provide the size of composite samples. The sample size declines with increasing precipitation, except for the $P>35 \mathrm{~mm}^{-1}$ day $^{-1}$ category owing to its broader bin size than other $P$ classes. Higher SSTs are preferred by heavy precipitation while moderate SSTs are most sampled for lower precipitation rates (Table A2). Lower SCAIs have a larger sample size particularly for light precipitation (Table A3). 


\section{APPENDIX B}

\section{Composite Time Series Stratified by Local Time}

To quantify the effects of diurnal variation on the composite evolution SCAI, Fig. B1 presents the breakdown by different local times at $t=0$ for $P_{0}>35 \mathrm{~mm} \mathrm{day}^{-1}$. Local time is sampled at $0,6,12$, and $18 \mathrm{~h}$ with a half-day window, allowing 6-h overlaps to maximize the sample size for statistical robustness. SCAI and the number of clusters have a distinct diurnal cycle that varies in phase among different local times. All curves, nevertheless, agree in that SCAI has a minimum near $t=0$ and hence the sign of the transient aggregation persists regardless of local time. The diurnal undulation is somewhat magnified in amplitude for the night and morning curves (1800-0500 and $0000-1100$ LT) immediately after $t=0$. Diurnal modulation is minimal in $D_{0}$ and $A_{c}$ as expected from the results above.

\section{REFERENCES}

Ahmed, F., and C. Schumacher, 2015: Convective and stratiform components of the precipitation-moisture relationship. Geophys. Res. Lett., 42, 10 453-10462, https://doi.org/ 10.1002/2015GL066957.

Arnold, N. P., and D. A. Randall, 2015: Global-scale convective aggregation: Implications for the Madden-Julian Oscillation. J. Adv. Model. Earth Syst., 7, 1499-1518, https://doi.org/ 10.1002/2015MS000498.

Beucler, T., and T. Cronin, 2019: A budget for the size of convective self-aggregation. Quart. J. Roy. Meteor. Soc., 145, 947966, https://doi.org/10.1002/qj.3468.

— T. H. Abbott, T. W. Cronin, and M. S. Pritchard, 2019: Comparing convective self-aggregation in idealized models to observed moist static energy variability near the equator. Geophys. Res. Lett., 46, 10589-10598, https://doi.org/10.1029/2019GL084130.

Bretherton, C. S., and M. F. Khairoutdinov, 2015: Convective selfaggregation feedbacks in near-global cloud-resolving simulations of an aquaplanet. J. Adv. Model. Earth Syst., 7, 17651787, https://doi.org/10.1002/2015MS000499.

_ , M. E. Peters, and L. E. Back, 2004: Relationships between water vapor path and precipitation over the tropical oceans. J. Climate, 17, 1517-1528, https://doi.org/10.1175/15200442(2004)017<1517:RBWVPA > 2.0.CO;2.

—, P. N. Blossey, and M. Khairoutdinov, 2005: An energybalance analysis of deep convective self-aggregation above uniform SST. J. Atmos. Sci., 62, 4273-4292, https://doi.org/ 10.1175/JAS3614.1.

Chen, S. S., R. A. Houze Jr., and B. E. Mapes, 1996: Multiscale variability of deep convection in relation to large-scale circulation in TOGA COARE. J. Atmos. Sci., 53, 1380-1409, https://doi.org/ 10.1175/1520-0469(1996)053<1380:MVODCI >2.0.CO;2.

Coppin, D., and S. Bony, 2015: Physical mechanisms controlling the initiation of convective self-aggregation in a general circulation model. J. Adv. Model. Earth Syst., 7, 2060-2078, https://doi.org/10.1002/2015MS000571.

— model in radiative-convective equilibrium. Geophys. Res. Lett., $\mathbf{4 4}$, 5142-5149, https://doi.org/10.1002/2017GL073658.

Craig, G. C., and J. M. Mack, 2013: A coarsening model for selforganization of tropical convection. J. Geophys. Res. Atmos., 118, 8761-8769, https://doi.org/10.1002/jgrd.50674.

Dee, D. P., and Coauthors, 2011: The ERA-Interim reanalysis: Configuration and performance of the data assimilation system. Quart. J. Roy. Meteor. Soc., 137, 553-597, https:// doi.org/10.1002/qj.828.

Doyle, A., 2018: Spatio-temporal development of convective aggregation in the tropics. M.S. thesis, Dept. of Meteorology, University of Reading, $32 \mathrm{pp}$.

Emanuel, K., A. A. Wing, and E. M. Vincent, 2014: Radiativeconvective instability. J. Adv. Model. Earth Syst., 6, 75-90, https://doi.org/10.1002/2013MS000270.

Gray, W. M., and R. W. Jacobson Jr., 1977: Diurnal variation of deep cumulus convection. Mon. Wea. Rev., 105, 1171-1188, https:// doi.org/10.1175/1520-0493(1977)105<1171:DVODCC >2.0.CO;2.

Held, I. M., R. S. Hemler, and V. Ramaswamy, 1993: Radiativeconvective equilibrium with explicit two-dimensional moist convection. J. Atmos. Sci., 50, 3909-3927, https://doi.org/ 10.1175/1520-0469(1993)050<3909:RCEWET>2.0.CO;2.

Holloway, C. E., 2017: Convective aggregation in realistic convective-scale simulation. J. Adv. Model. Earth Syst., 9, 1450-1472, https://doi.org/10.1002/2017MS000980.

— aggregation to diabatic processes in idealized radiativeconvective equilibrium simulations. J. Adv. Model. Earth Syst., 8, 166-195, https://doi.org/10.1002/2015MS000511.

—, A. A. Wing, S. Bony, C. Muller, H. Masunaga, T. S. L'Ecuyer, D. D. Turner, and P. Zuidema, 2017: Observing convective aggregation. Surv. Geophys., 38, 1199-1236, https://doi.org/ 10.1007/s10712-017-9419-1.

Houze, R. A., Jr., 2004: Mesoscale convective systems. Rev. Geophys., 42, RG4003, https://doi.org/10.1029/2004RG000150.

Huffman, G. J., and Coauthors, 2007: The TRMM Multisatellite Precipitation Analysis: Quasi-global, multi-year, combinedsensor precipitation estimates at fine scale. J. Hydrometeor., $\mathbf{8}$, 38-55, https://doi.org/10.1175/JHM560.1.

Janowiak, J. E., P. A. Arkin, and M. Morrissey, 1994: An examination of the diurnal cycle in oceanic tropical rainfall using satellite and in situ data. Mon. Wea. Rev., 122, 2296-2311, https://doi.org/ 10.1175/1520-0493(1994)122<2296:AEOTDC >2.0.CO;2.

_, R. A. Joyce, and Y. Yarosh, 2001: A real-time global halfhourly pixel-resolution infrared dataset and its applications. Bull. Amer. Meteor. Soc., 82, 205-218, https://doi.org/10.1175/ 1520-0477(2001)082<0205:ARTGHH > 2.3.CO;2.

Jeevanjee, N., and D. M. Romps, 2013: Convective selfaggregation, cold pools, and domain size. Geophys. Res. Lett., 40, 994-998, https://doi.org/10.1002/grl.50204.

Kadoya, T., and H. Masunaga, 2018: New observational metrics of convective self-aggregation: Methodology and a case study. J. Meteor. Soc. Japan, 96, 535-548, https://doi.org/10.2151/ jmsj.2018-054.

Khairoutdinov, M., and K. Emanuel, 2013: Rotating radiativeconvective equilibrium simulated by a cloud-resolving model. J. Adv. Model. Earth Syst., 5, 816-825, https://doi.org/10.1002/ 2013MS000253.

— and —, 2018: Intraseasonal variability in a cloud-permitting near-global equatorial aquaplanet model. J. Atmos. Sci., $\mathbf{7 5}$, 4337-4355, https://doi.org/10.1175/JAS-D-18-0152.1.

Knapp, K. R., and Coauthors, 2011: Globally gridded satellite observations for climate studies. Bull. Amer. Meteor. Soc., 92, 893-907, https://doi.org/10.1175/2011BAMS3039.1.

Mapes, B. E., 1993: Gregarious tropical convection. J. Atmos. Sci., 50, 2026-2037, https://doi.org/10.1175/1520-0469(1993)050<2026: GTC $>2.0 . \mathrm{CO} ; 2$.

Muller, C. J., and I. M. Held, 2012: Detailed investigation of the selfaggregation of convection in cloud-resolving simulations. J. Atmos. Sci, 69, 2551-2565, https://doi.org/10.1175/JAS-D-11-0257.1. 
and S. Bony, 2015: What favors convective aggregation and why? Geophys. Res. Lett., 42, 5626-5634, https://doi.org/ 10.1002/2015GL064260.

Nakazawa, T., 1988: Tropical super clusters within intraseasonal variations over the western Pacific. J. Meteor. Soc. Japan, 66, 823-839, https://doi.org/10.2151/jmsj1965.66.6_823.

Nolan, D. S., E. D. Rappin, and K. A. Emanuel, 2007: Tropical cyclogenesis sensitivity to environmental parameters in radiative-convective equilibrium. Quart. J. Roy. Meteor. Soc., 133, 2085-2107, https://doi.org/10.1002/qj.170.

Peters, O., and J. D. Neelin, 2006: Critical phenomena in atmospheric precipitation. Nat. Phys., 2, 393-396, https://doi.org/ 10.1038/nphys314.

Pscheidt, I., F. Senf, R. Heinze, H. Deneke, S. Trömel, and C. Hohenegger, 2019: How organized is deep convection over Germany? Quart. J. Roy. Meteor. Soc., 145, 2366-2384, https:// doi.org/10.1002/qj.3552.

Reynolds, R. W., and T. M. Smith, 1994: Improved global sea surface temperature analyses using optimum interpolation. J. Climate, 7, 929-948, https://doi.org/10.1175/1520-0442(1994) 007<0929:IGSSTA > 2.0.CO;2.

Stein, T. H. M., C. E. Holloway, S. Bony, and I. Tobin, 2017: Observed relationships between cloud vertical structure and convective aggregation over tropical ocean. J. Climate, 30, 2187-2207, https://doi.org/10.1175/JCLI-D-16-0125.1.

Stephens, G. L., S. van den Heever, and L. Pakula, 2008: Radiativeconvective feedbacks in idealized states of radiative-convective equilibrium. J. Atmos. Sci., 65, 3899-3916, https://doi.org/10.1175/ 2008JAS2524.1.

Tobin, I., S. Bony, and R. Roca, 2012: Observational evidence for relationships between the degree of aggregation of deep convection, water vapor, surface fluxes, and radiation. J. Climate, 25, 6885-6904, https://doi.org/10.1175/JCLI-D-11-00258.1.

$\longrightarrow,-$ C. E. Holloway, J.-Y. Grandpeix, G. Sèze, D. Coppin, S. J. Woolnough, and R. Roca, 2013: Does convective aggregation need to be represented in cumulus parameterizations? J. Adv. Model. Earth Syst., 5, 692-703, https://doi.org/10.1002/jame.20047.

Tompkins, A. M., 2001: Organization of tropical convection in low vertical wind shears: The role of water vapor. J. Atmos. Sci., 58, 529-545, https://doi.org/10.1175/1520-0469(2001) $058<0529$ :OOTCIL $>2.0$. CO 2 .

— , and G. C. Craig, 1998: Radiative-convective equilibrium in a threedimensional cloud-ensemble model. Quart. J. Roy. Meteor. Soc., 124, 2073-2097, https://doi.org/10.1002/qj.49712455013.
, and A. Semie, 2017: Organization of tropical convection in low vertical wind shears: Role of updraft entrainment. $J$. $A d v$. Model. Earth Syst., 9, 1046-1068, https://doi.org/10.1002/ 2016MS000802.

Wall, C. J., D. L. Hartmann, M. M. Thieman, W. L. Smith Jr., and P. Minnis, 2018: The life cycle of anvil clouds and the top-ofatmosphere radiation balance over the tropical west Pacific. J. Climate, 31, 10 059-10 080, https://doi.org/10.1175/JCLI-D18-0154.1.

Wentz, F. J., 2000: Satellite measurements of sea surface temperature through clouds. Science, 288, 847-850, https://doi.org/ 10.1126/science.288.5467.847.

White, B. A., A. M. Buchanan, C. E. Birch, P. Stier, and K. J. Pearson, 2018: Quantifying the effects of horizontal grid length and parameterized convection on the degree of convective organization using a metric of the potential for convective interaction. J. Atmos. Sci., 75, 425-450, https://doi.org/ 10.1175/JAS-D-16-0307.1.

Wing, A. A., 2019: Self-aggregation of deep convection and its implications for climate. Curr. Climate Change Rep., 5, 1-11, https://doi.org/10.1007/s40641-019-00120-3.

_, and K. A. Emanuel, 2014: Physical mechanisms controlling self-aggregation of convection in idealized numerical modeling simulations. J. Adv. Model. Earth Syst., 6, 59-74, https:// doi.org/10.1002/2013MS000269.

— long channel geometry. Quart. J. Roy. Meteor. Soc., 142,1-15, https://doi.org/10.1002/qj.2628.

—, K. Emanuel, C. E. Holloway, and C. Muller, 2017: Convective self-aggregation in numerical simulations: A review. Surv. Geophys., 38, 1173-1197, https://doi.org/10.1007/ s10712-017-9408-4.

Xu, K.-M., Y. Hu, and T. Wong, 2019: Convective aggregation and indices examined from CERES cloud object data. J. Geophys. Res. Atmos., 124, 13604-13 624, https://doi.org/10.1029/ 2019JD030816.

Yang, D., 2018: Boundary layer diabatic processes, the virtual effect, and convective self-aggregation. J. Adv. Model. Earth Syst., 10, 2163-2176, https://doi.org/10.1029/2017MS001261.

Young, G. S., S. M. Perugini, and C. W. Fairall, 1995: Convective wakes in the equatorial western Pacific during TOGA. Mon. Wea. Rev., 123, 110-123, https://doi.org/10.1175/1520-0493(1995)123<0110: CWITEW $>2.0 . \mathrm{CO} ; 2$ 